\title{
A Review on Exergy Analysis of Solar Refrigeration Technologies
}

\author{
Paiguy Armand Ngouateu Wouagfack ${ }^{1, *}$, Maurice Tenkeng ${ }^{2,3}$, Daniel Lissouck ${ }^{1}$, Réné Tchinda ${ }^{2,3}$ \\ ${ }^{1}$ Department of Renewable Energy, Higher Technical Teachers, Training College, University of Buea, Kumba, Cameroon \\ ${ }^{2}$ L2MSP, Department of Physics, University of Dschang, Dschang, Cameroon \\ ${ }^{3}$ LISIE, University Institute of Technology Fotso Victor, University of Dschang, Dschang, Cameroon
}

Email address:

ngouateupaiguy@yahoo.fr (P. A. N. Wouagfack)

${ }^{*}$ Corresponding author

To cite this article:

Paiguy Armand Ngouateu Wouagfack, Maurice Tenkeng, Daniel Lissouck, Réné Tchinda. A Review on Exergy Analysis of Solar Refrigeration Technologies. Industrial Engineering. Vol. 4, No. 2, 2020, pp. 14-32. doi: 10.11648/j.ie.20200402.11

Received: March 11, 2020; Accepted: April 24, 2020; Published: August 27, 2020

\begin{abstract}
Solar energy is becoming more and more useful in the modern day life in industrial, domestic and commercial sectors, because of his cleanliness from an environmental point of view and also contributes to the reduction of greenhouse effect gases such as $\mathrm{CO}_{2}$. Exergy analysis is a thermodynamic analysis technique based on the Second Law of Thermodynamics, which provides an alternative and illuminating means of assessing and comparing processes and systems rationally and meaningfully. Exergy analysis can assist in improving and optimizing designs. In this paper, the exergy analysis of solar thermal refrigeration cyles is reviewed. A review of the research state of art of the solar absorption and adsorption refrigeration technologies is also carried out. The cycles involved in these technologies are: open, closed, continuous and intermittent cycles. An overview of mesures of merit with regard to exergy (exergetic efficiency, exergy losses, exergy improvement and exergetic coefficient of performance) is presented. Besides, an historical and chronological view is done on the development scenario of exergy analysis in the world from 1824 until 2014. The main mathematical relations for the simulation of those cycles are presented.
\end{abstract}

Keywords: Exergy Analysis, Solar Refrigeration, Absorption, Adsorption

\section{Introduction}

Solar energy is becoming more and more solicited by industries in general and for houses purposes in particular. The fight for a clean environment and activities without warming is nowadays a necessity. That's why refrigeration systems is a great preoccupation for engineers in laboratories. Recently, the use of solar energy for both heating and cooling applications has received more attentions, this is because, the electricity demands for both heating and cooling by the domestic sector, during winter and summer, respectively, are quite high. The conventional electric heater and air conditioner used in the buildings/domestic sector consume a lot of electricity [1]. In the countries producing oil in the world, most of their electricity demands are supplied by conventional power plants driven by fossil fuels. The problem is that oil will be ceased to dominate as the main energy source by the end of the $21 \mathrm{st}$ century. Also, with the growth of world's population and civil modernization, the world energy demand will definitely escalate in the next 20 years [2]. With the decrease of fossil fuel resources, the energy demand is rapidly increasing, and this will definitely lead to an energy crisis in the near future [3]. Therefore, the coupling of the renewable energy sources such as solar energy with either heating or cooling systems is a promising alternative method. Because of the desirable environmental and safety aspects, it is widely accepted that solar energy should be utilized instead of other alternative energy forms as it can be provided sustainably without harming the environment [4]. Furthermore, fossil fuel combustion can cause greenhouse effect that highly contributes to the global warming. There are plenty of technologies currently available to capture and hold the sun's power for uses such as water heating, cooking, space heating, power generation, food drying and refrigeration [5].

The concept of exergy was put forward by Gibbs in 1878. It was further developed by Rant in 1956, who used the term 'exergy' for the first time which refers to the Greek words ex 
(external) and ergos (work). The term exergy relates to ideal work and exergy losses relate to lost work [6]. Szargut [7] defined the exergy of a system at a certain thermodynamic state as the maximum amount of work that can be obtained when the system moves from that particular state to a state of equilibrium with the surroundings. As it is well known, exergy is the measure of useful work or potential of a stream to cause change. Besides it is an effective measure of the potential of a substance to impact the environment [8,9]. M. Tenkeng et al. [10] conducted a study on exergy analysis of a single effect solar absorption refrigeration system in Ngaoundere, Cameroun. The exergy loss of each component of the system was analysed in a half hourly basis. They observed that the evaporator and generator registered the great losses and were the components that needed to be optimized. Tenkeng et al. [11] also presented a study on exergy analysis of a series double effect solar refrigeration in Ngaoundere, Cameroun on a half hourly basis, from 6.30AM to 6.30PM. A thermodynamic analysis was undertaken by simulation with a FORTRAN program and the results showed that the High Pressure Generator and the evaporator were the component needing a great attention in term of exergy efficiency and exergy loss.

The aim of this paper is to provide basic background and review existing literatures on exergy analysis of solar refrigeration technologies. A number of refrigeration systems is also presented and it is hoped that, this should be useful for any newcomer in the field of solar refrigeration technology and of great help for investigators on the field of exergy analysis in the future.

\section{Presentation of Solar Refrigeration Technologies}

Solar refrigeration has become more attractive for cooling purposes today because of the use of desiccant gases, such as $\mathrm{LiCl}$ (lithium chloride) and $\mathrm{LiBr}$ (lithium bromide), or water instead of harmful Freon gas. Cooling can be achieved through two basic methods. The first is a PV (Photovoltaic)-based solar energy system, where solar energy is converted into electrical energy and used for refrigeration much like conventional methods [12]. The second one utilizes a solar thermal refrigeration system, where a solar collector directly heats the refrigerant through collector tubes instead of using solar electric power [13]. According to Hassan et al. [14] there are three types of cooling production devices: closed cycle continuous absorption cooling system, closed cycle intermittent absorption cooling system and open cycle absorption cooling system. The intermittent cycle may work based on the single or the double stage technology. In an intermittent absorption system, there is no moving part because the solution pump is eliminated and the density difference is utilized for the solution circulation based on the thermosiphon principle. The closed cycle continuous absorption refrigeration systems require heat source temperatures that are significantly higher than the temperatures of corresponding condenser. Our review is focusing on the thermal method and this presentation is focusing on both closed and open cycles. Absorption refrigeration technologies consist of a generator, a pump and an absorber that are collectively capable of compressing the refrigerant vapour. The evaporator draws the vapour refrigerant [15]. According to the solution regeneration and thermal operation cycle, the absorption systems can be divided into three categories: single-effect, half-effect and double-effect solar absorption cycles. The single-effect and halfeffect chillers require lower temperatures with respect to a double effect-chiller [16]. There are also two other absorption refrigeration systems (DAR (diffusion absorption refrigeration) and hybrid systems) that can achieve better performance [17]. Therefore, the finding of root cause of irreversibilities can be helpful in the optimum designing and effective utilization of energy in various applications. Moreover, the exergy analysis also provides true sense of diversion of existing system from the ideal one [18]. The solar energy can be utilized (directly or indirectly) in different applications such as solar drying, solar refrigeration and air conditioning, solar water heating, solar cooking and solar power generation.

The very important advantage of the solar absorption cooling technology is that their coefficient of performance is higher than that of other thermally operated cycles. Furthermore, the freedom from noise and vibrations, long lasting, cheap maintenance, and most importantly the possibility of using any type of heat source, including solar radiation and geothermal or waste heat, to energize the system and provide reliable cooling [14].

Absorption is the phenomenon in which a substance in one state interpenetrates and incorporates into another of a different state. The two phases present a strong affinity to form a solution or a mixture. This process can be reversed and the absorbed phase can be released from the absorbent by applying heat to the mixture. The first absorption cooling machine using water as the absorbent and ammonia as refrigerant was patented in France in 1859 by the French scientist Ferdinand Carre'. The solar absorption cooling system uses two working fluids, the refrigerant and the sorbent, in a closed or open mode cycle. Absorption machines are thermally activated, and for this reason, high input shaft power is not required [19]. Its working principle is the same as the vapour compression machine except the fact that the mechanical compressor replaced the thermal compressor [5]. The applications of these cooling systems are wide and include freezing, cooling, and airconditioning. This type of open absorption cooling system is open to the regenerator side. A schematic diagram of the solar-operated open absorption refrigeration system is shown in Figure 8. In this type of cooling machines, the dilute absorbent solution is heated and subsequently re-concentrated in the solar collector, which is open to the atmosphere, due to the evaporating process [5]. In the open cycle absorption cooling system, one can have two possible options depending on whether the absorption system is made open from the regenerator part or from the evaporator part. The first option is the open regeneration absorption cooling system, where the system is made open to the regenerator side. The second option is the open evaporative cooling system, in which the system is open to the evaporator part [20]. There are three types of cooling production devices: closed cycle 
continuous absorption cooling system, closed cycle intermittent absorption cooling system and open cycle absorption cooling system [5]. A comparative study of the open and closed cycle options has been made. It is concluded that the hybrid doubleabsorption solar cooling systems are better in performance than conventional systems and an open-cycle double-absorption system is even more attractive and cost effective as compared to closed-cycle option. [21].

\subsection{Solar Absorption Refrigeration Systems}

\subsubsection{Continuous Operation Systems}

\section{i. Half Effect Absorption Refrigeration Systems}

The primary feature of the half-effect absorption cycle is the running capability at lower temperatures compared to others. The name "half-effect" arises from the COP, which is almost half that of the single-effect cycle [5].

R. Maryami et al. [22] proposed the schematic diagram of Figure 1 showing the half effect absorption refrigeration cycle which consists of two solution circuits, one of them operates between medium and high pressure level and the other one operates from low to medium pressure level. Therefore, main components of half effect cycle are two generators, two absorbers, two solution heat exchangers, and only one condenser and one evaporator. In this cycle, high generator (HG) and condenser operate at high pressure side while low generator (LG) and high absorber (HA) operate at medium pressure level. On the other hand, low absorber (LA) and evaporator operate at low pressure side. In this cycle, the heat transferred to both generator can be same temperature. An amount heat supplied to HG to separate refrigerant vapour and once refrigerant vapour is produced (13), it is condensed in condenser (14) and by passing from refrigerant expansion valve (15) flows into evaporator. The evaporation process in evaporator leads to liquid-vapour mixture converts to refrigerant vapour which it after leaving the evaporator goes to LA (16). At LA the refrigerant vapour is absorbed by the solution with low concentration coming from LG (6). Then the solution produced with intermediate concentration (1) is pumped to the LG, passing through a solution heat exchanger I (1-2-3). By means of the heat supplied to LG, part of the refrigerant separates from solution (17) and flows directly to HA where it is absorbed by the solution coming from $\mathrm{HG}$ (12). Finally, the LiBr/water solution formed with high concentration (7) is pumped to HG through the solution heat exchanger II starting the cycle again (7-8-9). In order to reduce the heat consumption in the generators solution heat exchangers are used between the absorbers and the generators to recover heat from the solution going from the generators to the absorbers.

ii. Single Effect Absorption Refrigeration Systems

Romero et al. [23] presented a single-effect absorption cooling system as a device which is simpler than others when the design depends on the types of working fluids. The system shows better performance with non-volatile absorbents such as $\mathrm{LiBr} /$ water. If a volatile working pair such as ammonia/water is used, then an extra rectifier should be used before the condenser to provide pure refrigerant. Boopathi et al. [24] proposed the schematic of a single effect lithium bromide absorption cycles of Figure 2. iii. Double Effect Absorption Refrigeration Systems

a) Series Double Effect Absorption Refrigeration Systems

R. Maryami et al. [22] proposed the line diagram of a series double effect absorption refrigeration cycle, employing two generators, two solution heat exchangers, two solution reducing valves, two refrigerant expansion valves, two condensers, an evaporator, an absorber and a solution pump as the main components. The cycle implies three pressure levels, the high condenser (HC) and $\mathrm{HG}$ operate at the high pressure part of the equipment and low condenser (LC) and LG at the medium pressure side while the evaporator and the absorber operate at the lower pressure side. As shown in Figure 3 the vapour refrigerant coming from evaporator (10) is combined with strong solution (6) in absorber and the produced weak solution (1) is pumped from absorber to HG through heat exchangers I and II (1-2-3-13). In HG a part of refrigerant vapour boiled out of the solution at relatively high temperature. The primary vapour (17) and the medium concentration solution (14) from HG come into the $\mathrm{HC}$ and $\mathrm{LG}$, respectively. The medium concentration solution goes into LG through the heat exchanger II and solution reducing valve (14-15-16). Heat rejected from primary vapour in $\mathrm{HC}$ is transferred to the medium concentration solution in LG and this heat transfer leads to vapour being $g$ condensed. The secondary vapour produced at outlet of LG (7) together with condensed water of primary vapour (18) at outlet of HC flow into the LC which heat rejection takes place. The secondary vapour directly and the condensed water through refrigerant valve (18-19) come into LC. At the outlet of LG the strong solution (4) is produced, which through heat exchanger I and the solution reducing valve (4-5-6) flows into absorber. Refrigerant liquid leaving LC (8) which is sum of refrigerant originating from LG and $\mathrm{HC}$, on refrigerant expansion valve, continues to the evaporator (8-9) where it is evaporated in low pressure. Vaporization in evaporator occurs by extracting the heat from medium and it leads to the medium being cooled. The vapour refrigerant from evaporator goes into absorber and is absorbed by the strong solution and the mentioned process is repeated.

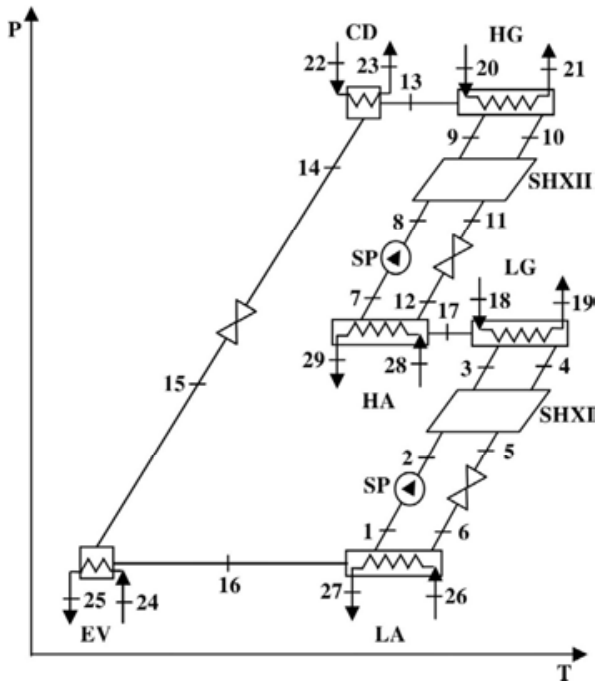

Figure 1. P-T diagram for a half-effect absorption cooling system [22]. 


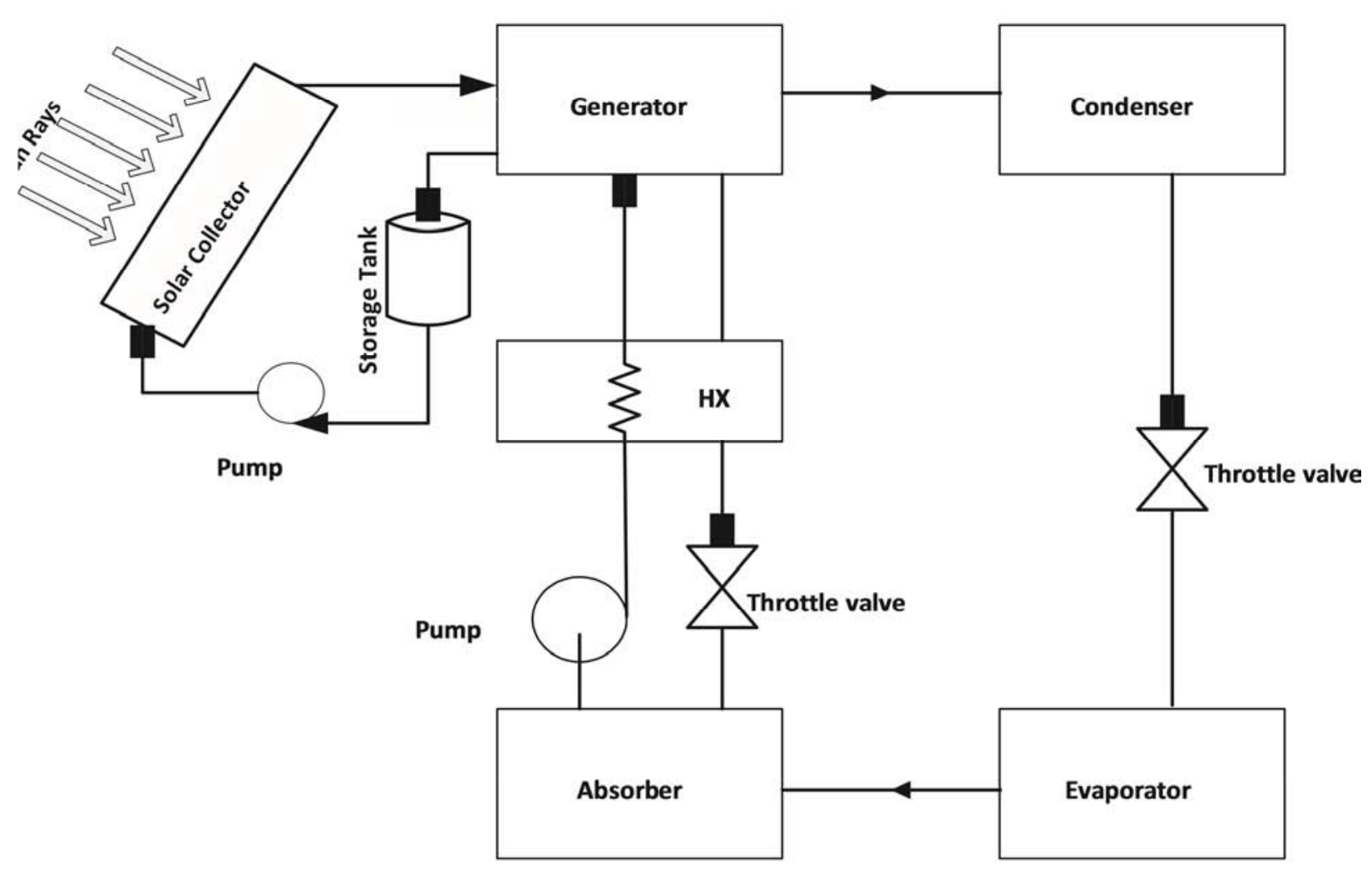

Figure 2. A solar assisted single $\mathrm{LiBr}-\mathrm{H}_{2} \mathrm{O}$ absorption cycle [24].

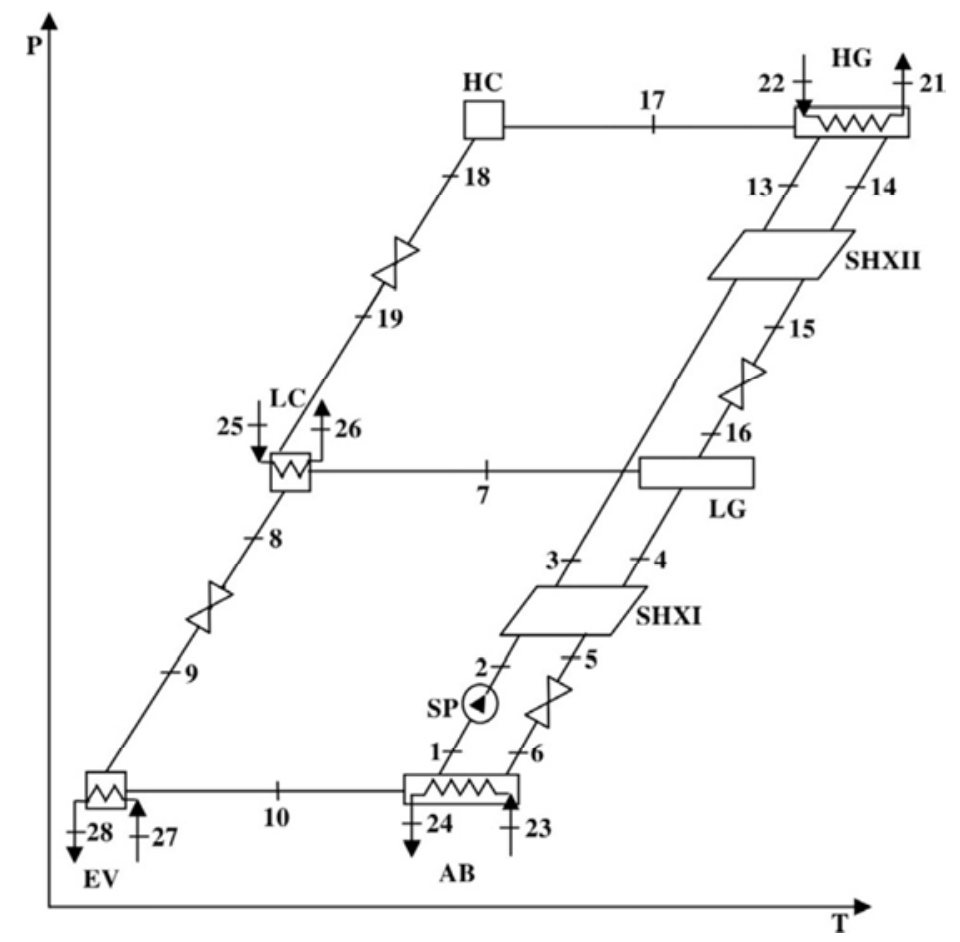

Figure 3. P-T diagram for a series double-effect absorption cooling system. [22].

b) Parallel Double Effect Absorption Refrigeration Systems

R. Maryami et al. [22] presented the schematic illustration of parallel double effect absorption refrigeration cycle as shown in Figure 4. The cycle consists of absorber, evaporator, two condensers, two refrigerant expansion valves, two solution reducing valves, two generators, two solution pumps and two solution heat exchangers. Similar to the series double effect absorption refrigeration system, the components of parallel double effect cycle operate at three 
pressure levels, i.e. lower, medium and high level pressures. Parallel and series double effect cycle description is approximately identical and the process in parallel double effect system is as follows. At an intermediate temperature (i.e. the temperature of $\mathrm{HG}$ ), waste heat (i.e. the output heat from an industrial process), is added to the HG to concentrate the weak absorbent solution flowing from the absorber (13), for partially vapour rizing working fluid. Note, the weak absorbent solution in HG (13) is at high pressure side and from absorber at lower pressure side (1) comes into HG through the solution heat exchanger I, LG and solution heat exchanger II using pumps (1-2-3-11-1213). In the LG, the weak absorbent solution (3 and 11) is at medium pressure level. At outlet of $\mathrm{HG}$, the strong absorbent solution (14), to be supplied to the absorber, is generated. The strong absorbent solution goes into absorber through the solution reducing valves, LG, solution heat exchangers I and II (1415-16-4-5-6). The vaporized working fluid at outlet of $\mathrm{HG}$ (17) flows to the $\mathrm{HC}$, where heat at a relatively high temperature is delivered to LG in order to produce secondary vapour (7), weak absorbent solution (11) and strong absorbent solution (4) at the outlets of LG and also condensed water at outlet of HC (18). Subsequently, from the $\mathrm{HC}$ and LG components, the liquid of primary vapour and secondary vapour go into the LC respectively which is maintained to a medium pressure. In the outlet of LC refrigerant fluid is produced at a intermediate temperature which flows into evaporator through refrigerant expansion valve (8-9). In the evaporator the working fluid is evaporated by using waste heat at the low temperature. The vaporized working fluid (10) flows to the absorber, where it is absorbed by the strong absorbent solution (6) which is coming from the generator. Because of absorption, the useful heat, at an intermediate temperature, is delivered. Finally, the weak absorbent solution is returned to the generator through the pumps.

iv. Triple Effect Absorption Refrigeration Systems

R. Maryami et al. [22] showed a schematic diagram of a triple effect absorption refrigeration system in Figure 5. It consists of three generators: $\mathrm{HG}$, middle generator (MG) and LG. It also consists of three condensers: HC, middle condenser (MC) and $\mathrm{LC}$ which from LC heat is rejected to the surrounding while from $\mathrm{HC}$ and $\mathrm{MC}$ heat is delivered to MG and LG respectively. This absorption refrigeration system implies four pressure levels. The $\mathrm{HG}$ and $\mathrm{HC}$ operate at high pressure. The MG and the MC operate at pressure related to temperature of saturated liquid extracted from MC (18) while LG and LC operate at middle pressure. The evaporator and the absorber work at low pressure. In this cycle, the weak absorbent solution (1) is pumped from the absorber to the HG through $\mathrm{LG}$ and $\mathrm{MG}$ and three solution heat exchangers I, II and III (1-2-3-11-12-13-2122-23). In the HG, similar to double effect systems the solution is heated at high temperature to boil out the refrigerant vapour from the solution. The primary vapour released from $\mathrm{HG}$ (27) enters $\mathrm{HC}$ and condenses. The strong solution leaving HG (24) flows into the GM through the solution heat exchanger III, where solution is cooled to some extent by exchanging heat with the weak solution (13). In the MG some more vapour (17) is released that flows to MC. The stronger absorbent solution which is now leaving MG (14) then goes to LG through solution heat exchanger II where the solution is further cooled by exchanging heat with the weak solution (3). Thus, more refrigerant is produced in LG that enters the LC (7) and heat is released to the sink. The total refrigerant entering $\mathrm{LC}$ is the sum of all those coming from the three generators. The liquid refrigerant from LC (8) flows into the evaporator through a refrigerant expansion valve which vaporizes after absorbing heat from the medium to be cooled. Refrigerant vapour (10) then goes to the absorber to be absorbed by the strongest solution coming from the LG (6) through the solution heat exchanger I and solution reducing valve. The cycle then gets completed and started again.

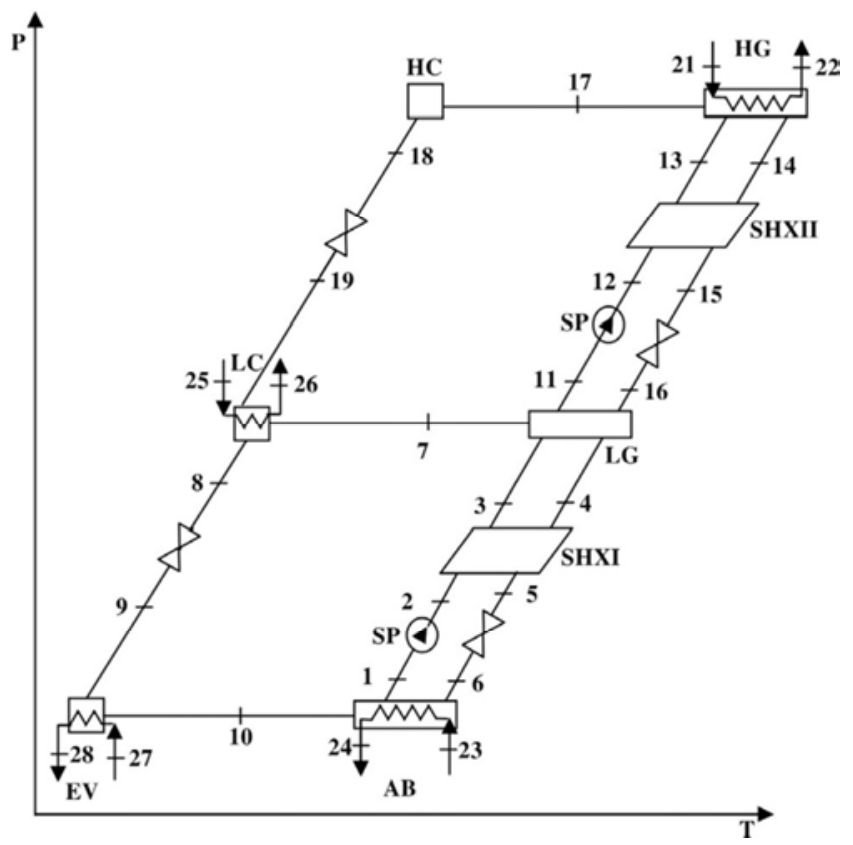

Figure 4. P-T diagram for a parallel double-effect absorption cooling system. [22].

v. Solar Open Absorption Cooling Systems

Kaushik et al. [20] explained that in the open cycle absorption cooling system, one can have two possible options depending on whether the absorption system is made open from the regenerator part or from the evaporator part. The first option is the open regeneration absorption cooling system, where the system is made open to the regenerator side. The second option is the open evaporative cooling system, in which the system is open to the evaporator part. These two systems are discussed in the following sections.

a) The Solar Open Regenerative Absorption Refrigeration System

Hassan et al. [5] presented this type of open absorption cooling system which is open to the regenerator side. A schematic diagram of the solar-operated open absorption refrigeration system is shown in Figure 6. In this type of 
cooling machines, the dilute absorbent solution is heated and subsequently re-concentrated in the solar collector, which is open to the atmosphere, due to the evaporating process. The strong regenerated solution leaves the collector and passes through a liquid column, to allow the strong solution to drop from atmospheric pressure to the reduced evaporator pressure. The strong solution then goes to the absorber after passing through a regenerative heat exchanger. In the absorber, the strong solution absorbs water vapour from the evaporator and therefore the latent heat of vaporization of the refrigerant is taken allowing a low temperature in the evaporator space by a vapour absorption process. The resultant weak solution is pumped from the absorber back to atmospheric pressure through the regenerative heat exchanger then through the regenerator to completing the cycle.

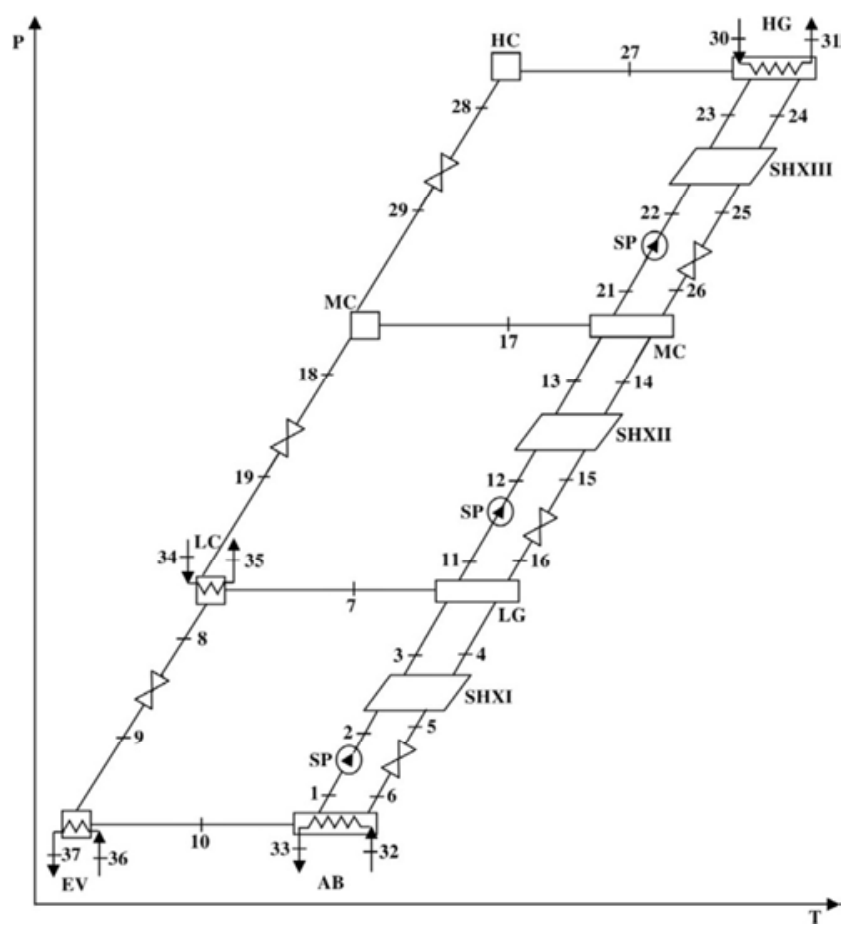

Figure 5. P-T diagram for a triple-effect absorption cooling system. [22].

b) The Solar Open Evaporative Absorption Refrigeration System

Hassan et al. [5] identified the main difference with the other cycles is the absence of condenser. In an open absorption cooling system, flows of heat and mass take place to and from the system at relatively low temperatures of the heat source. The entire operation takes place at atmospheric pressure, thus eliminating the need for vacuum vessels. Water is generally used as the refrigerant in this system. The reason is that the refrigerant is released to the ambient atmosphere and therefore it should be environmentally friendly. Another reason is the requirement of a continuous supply of make-up refrigerant during the entire operating time. As a consequence, water as a refrigerant is very suitable working fluid in the open cycle absorption cooling system. Absorbents like $\mathrm{LiBr}, \mathrm{LiCl}$ or $\mathrm{CaCl}_{2}$ are usually used with water refrigerant.

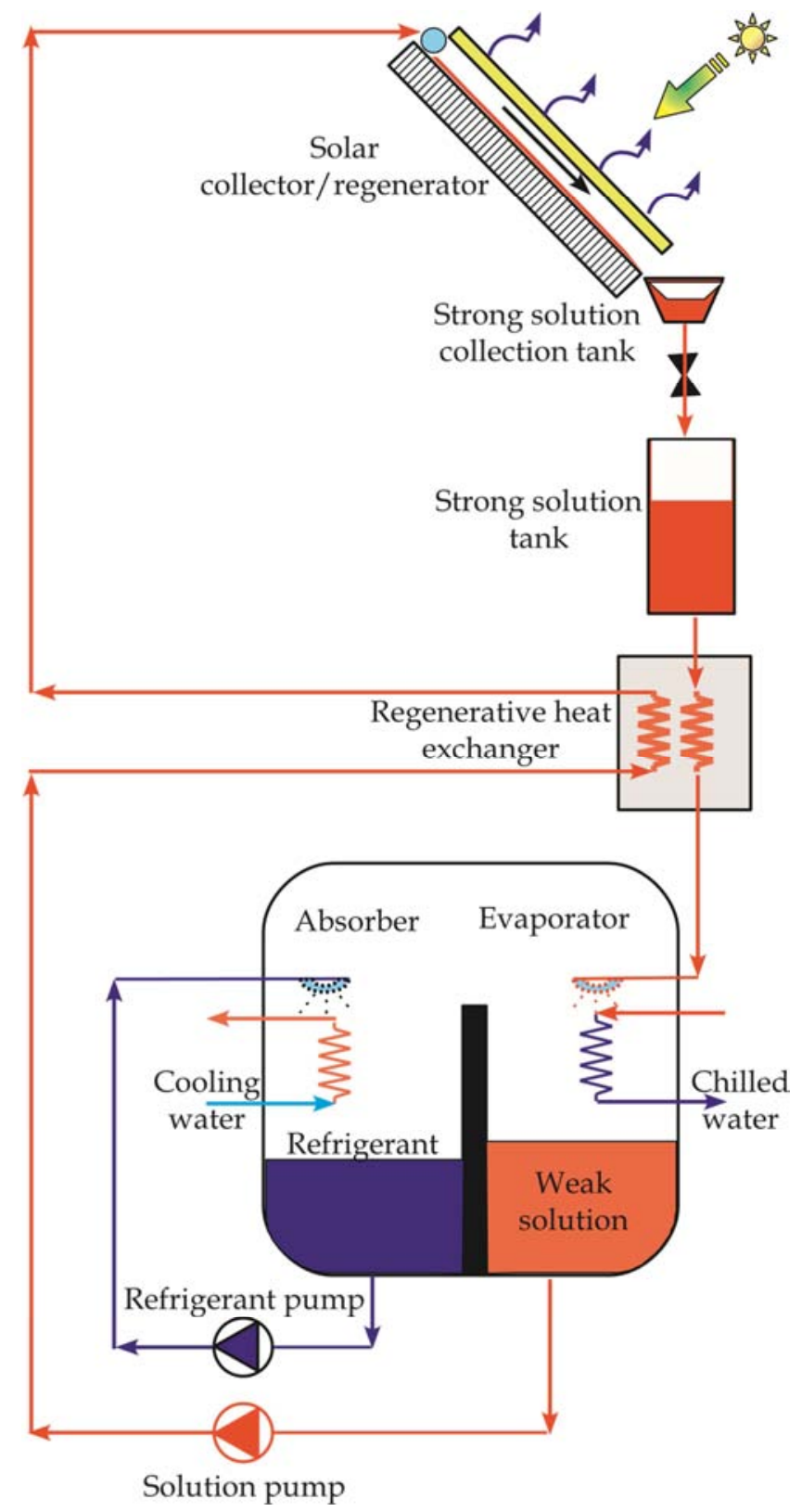

Figure 6. The solar powered open regenerative absorption refrigeration system. [25].

vi. The Diffusion Absorption Refrigeration Systems

Two Swedish engineers, Platen and Munters, developed a special kind of absorption cooling cycle in 1922. The cycle is so called as Platen-Munters cycle and the machine is called the diffusion absorption refrigeration (DAR) system. The main difference between the other cycles and the DAR machine is the lack of pumps or any moving parts that require auxiliary energy supply. Therefore, the system is noiseless and free from vibration. Moreover, it exhibits good reliability, durability, and minimum maintenance costs [26]. The whole unit has the same total pressure and as a consequence, the usual throttling required for the pressure reduction is removed and the solution pump can be a simple gas bubble thermally powered pump. Figure 7 shows a schematic diagram for the DAR machine and its main components. The main components of the DAR 
system are the generator, condenser, evaporator, absorber, rectifier, and a bubble pump that is besides the auxiliary gas heat exchanger (AGHX) and solution heat exchanger (SHX). The cycle uses a three-component working fluid consisting of the refrigerant, the absorbent, and the auxiliary gas. Ammonia is generally used as a refrigerant, water is used as an absorption media and the auxiliary gas is a kind of inert non condensable and non-absorbable gas like hydrogen or helium. The principle of the cycle operation is similar to the single stage absorption cycle. The difference is that the total pressure is the same in the entire system. Ammonia circulates through all the system components. Water-ammonia solution circulates through the generator, gas bubble pump, and absorber. The ammonia-hydrogen gas mixture circulates in the auxiliary gas circuit which includes the evaporator, absorber, and gas heat exchanger (not shown in figure), and is driven by natural convection. The generator temperature varies typically between 120 and $180{ }^{\circ} \mathrm{C}$, and the practical COP varies between 0.2 and 0.3 with cooling capacity of $25-100 \mathrm{~W}$. However, large capacity systems are not considered as attractive.

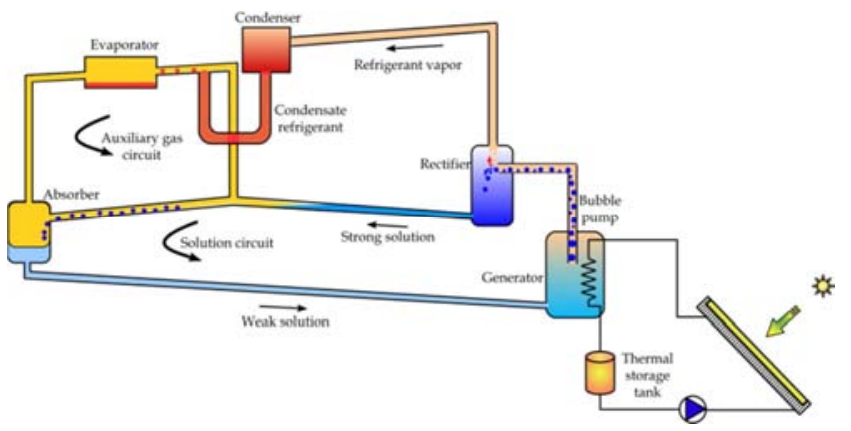

Figure 7. The diffusion absorption solar refrigeration system. [25].

vii.Dehumidifier-Evaporator-Regenerator (DER) System

Hellmann and Grossman [27] reported an investigation of an evaporative cooling open cycle absorption heat pump that is capable of utilizing low grade heat sources such as solar heat as its source of power was by. The system, referred to as dehumidifier-evaporator-regenerator (DER) cycle represented in Figure 8, operates at atmospheric pressure and its immediate application is for cooling and air conditioning.

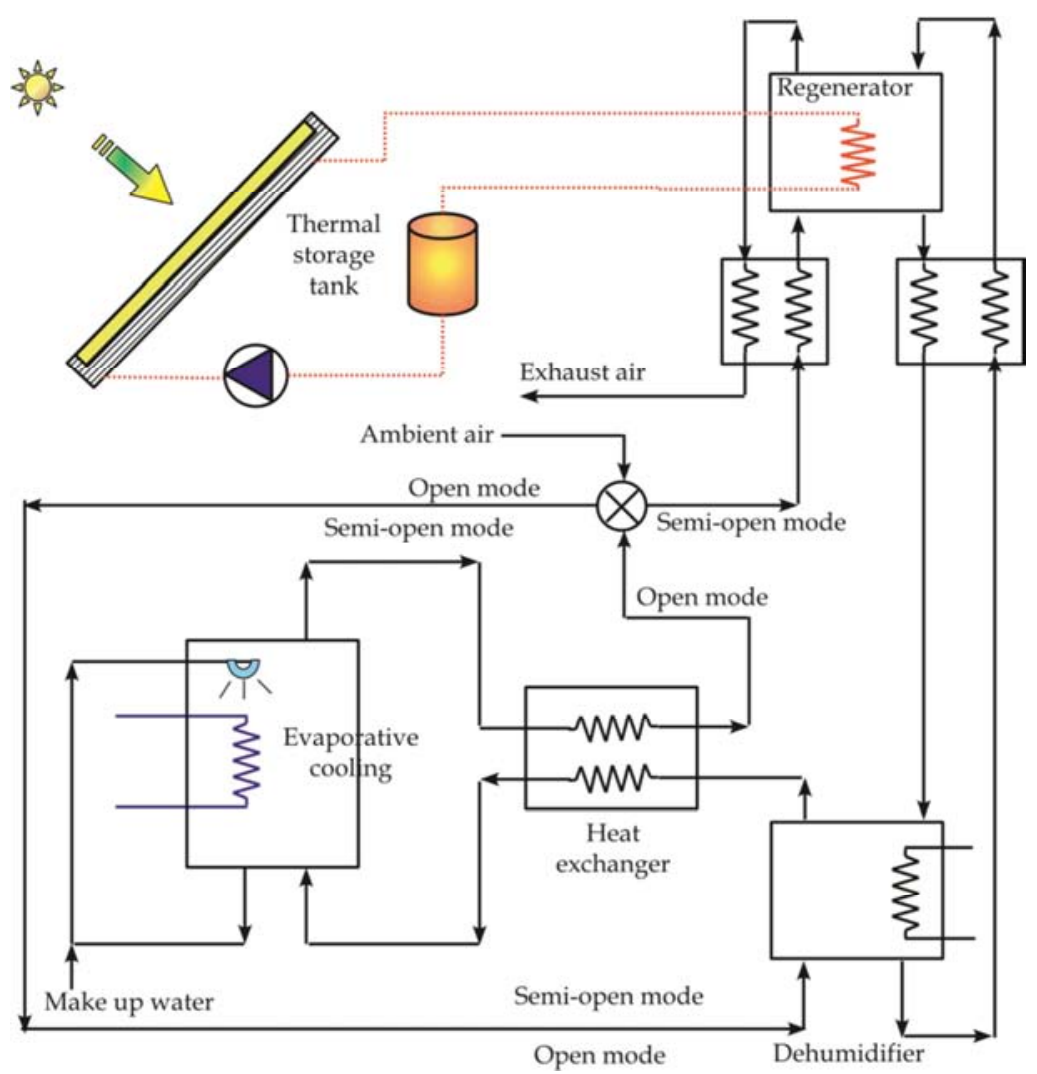

Figure 8. The dehumidifier-evaporator-regenerator (DER) system [25].

\subsubsection{The Intermittent Solar Absorption Refrigeration System}

According to Trombe and Foex [28], most of the earlier solar absorption chillers were manufactured for intermittent operation, however researchers later focused over continuous operation chillers because of low coefficient of performance of the intermittent chillers.

i. he Single Stage Intermittent Solar Absorption

\section{Refrigeration System}

A schematic diagram of the basic single effect intermittent solar absorption cycle is shown in Figure 9. The working principle of this system was presented for the first time by Venkatesh and Mani [29]. Staicovici [30] described an intermittent single-stage $\mathrm{H}_{2} \mathrm{O} / \mathrm{NH}_{3}$ solar absorption system of $46 \mathrm{MJ} /$ cycle. He used evacuated solar collectors with selective surfaces to heat the generator. 


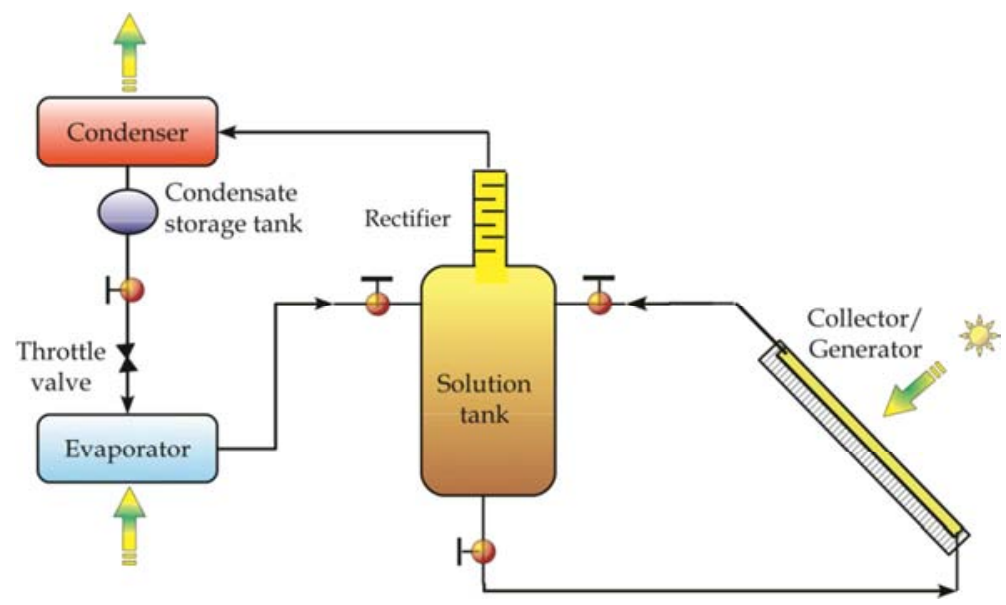

Figure 9. The single stage intermittent solar absorption cooling system. [25].

ii. The Two Stage Intermittent Solar Refrigeration System

Pridasawas W. et al. [31] presented the two-stage intermittent as a system that can be used to improve the operation and enhance the efficiency of the single stage system. Moreover, it can solve the limiting operation temperature in the single stage system. In the two stage system there are two levels of generator pressures, a highpressure generator (HPG) and a low-pressure generator (LPG). The HPG and LPG generators are sets of flat plate collectors. The generators are built into the flat plate solar collector. As shown in Figure 10, there are two weak solution storage tanks (Tank 1 and Tank 2) to store and supply to HPG and one tank (Tank 3 ) to store and supply the weak solution to LPG. Tank 1 and Tank 2 do not supply the weak solution to HPG at the same time; they alternate daily. Tank 3 is operated every day to supply the weak solution to Tank 1 or Tank 2, whichever is not supplying solution to HPG.

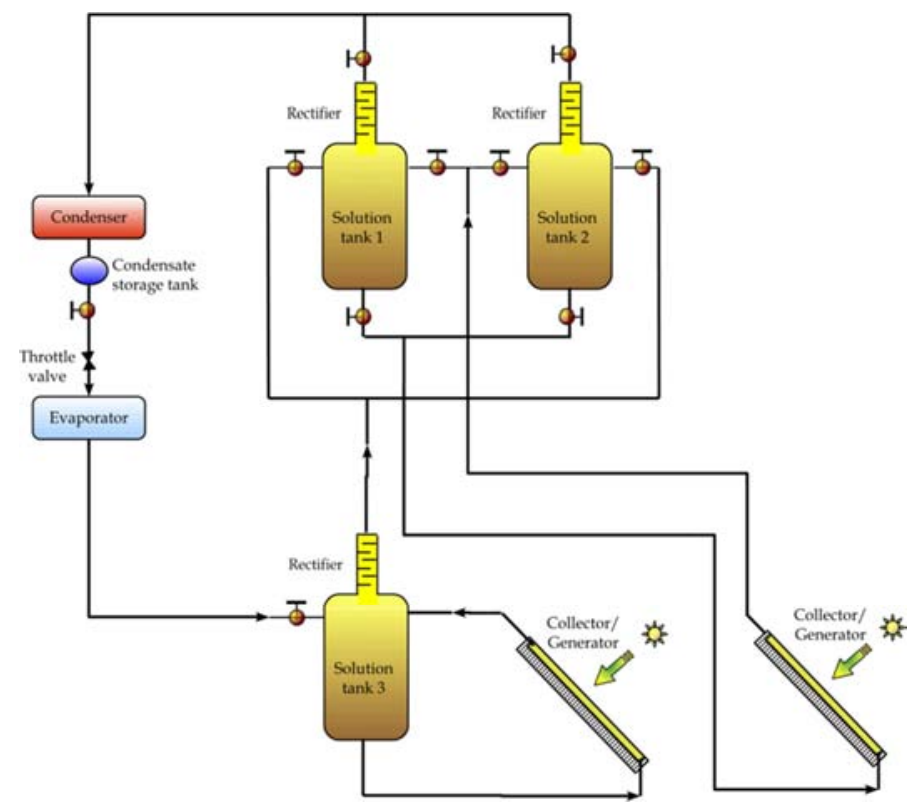

Figure 10. Construction of the two stage intermittent solar absorption cooling system. [25].

\subsubsection{Hybrid Solar Absorption Refrigeration Systems}

Kaushik and Yadav [21] presented two designs for a hybrid double-absorption solar cooling system. These are: a conventional closed-cycle and open-cycle absorption systems with an additional open-absorber component through which the process room air is passed, cooled and dehumidified. The cooling produced in the evaporator is utilized to remove heat from the open absorber and the process air being circulated. A comparative study of the open and closed cycle options has been made. They concluded that the hybrid doubleabsorption solar cooling systems are better in performance than conventional systems and an open-cycle doubleabsorption system is even more attractive and cost effective as compared to closed-cycle option.

\subsection{Solar Adsorption Refrigeration Technologies}

Vapour adsorption technology was introduced for the first time in 1848 by Faraday, using a solid adsorbent. Adsorption 
cycles were first used in refrigeration and heat pumps in the early 1990s. The disadvantages of liquid-vapour systems were overcome by using solid-vapour cycles; this technology was first marketed in the 1920s [32]. Adsorptionrefrigeration systems are environmentally friendly alternatives to the other existing systems, since they can use refrigerants that do not contribute to ozone layer depletion and global warming. They also operate at lower costs in comparison with the absorption systems, as they do not need solution pump. The refrigeration as solar energy application is particularly attractive because of non-dependence on conventional power. Adsorption refrigeration technology are used for many specific applications, such as purification, separation and thermal refrigeration technologies [33]. An adsorption cooling system is not only advantageous for its zero ODP (ozone depleting potential) but also for other positive features [34, 35]: K. R. Ullah et al. [15] verified that adsorption technology can accommodate high temperature heat sources (over 500V) without corrosion, whereas corrosion occurs above $200^{\circ} \mathrm{C}$ in absorption technology. Adsorption technology is better equipped to handle vibration issues in a cooling system than absorption technology. Because of the liquid absorbent present in an absorption system, vibrations can cause serious damages, such as flows from the absorber to condenser or from the generator to evaporator, potentially polluting the refrigerant. Adsorption is immune to this condition, and can thus be used in locomotives and fishing boats. An adsorption system is simpler to design than an absorption system.

\subsubsection{Working Principle of Solar Adsorption Cooling Systems}

The adsorption process differs from the absorption process in that absorption is a volumetric phenomenon, whereas adsorption is a surface phenomenon. The primary component of an adsorption system is a solid porous surface with a large surface area and a large adsorptive capacity. Initially, this surface remains unsaturated. When a vapour molecule contacts the surface, an interaction occurs between the surface and the molecules and the molecules are adsorbed on to the surface [25]. Adsorption is a process in which molecules of a fluid are attached to a surface. The surface is composed of a solid material. The molecules do not perform any chemical reaction; they merely discard energy when attached to the surface. The phase change (from fluid to adsorbate) is exothermic, and the process is fully reversible [36]. Figure11 presented a solar powered continuous adsorption refrigeration system.

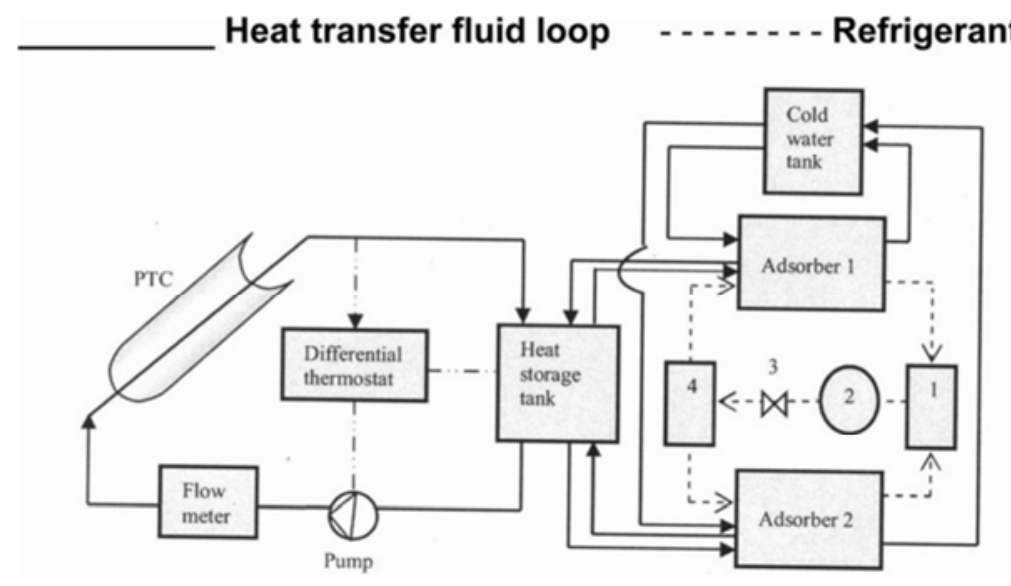

Figure 11. Schematic diagram of the solar powered continuous adsorption-refrigeration system (1) condenser, (2) ammonia tank, (3) expansion valve evaporator: [37].

\subsubsection{Adsorbents and Working Pairs}

Wang LW et al. [34] noticed that the most common working pairs used in adsorption technologies are silica gelwater, activated-carbon-methanol, activated carbon-ammonia zeolite-water, activated-carbon granular and fibber adsorbent. In an adsorption refrigeration technique, the working pair plays a vital role for optimal performance of the system. The best performance is achieved if the adsorbent demonstrates the following characteristics: A large adsorption ability; the ability to change capacity with the variation of temperature; a flatter isotherm; excellent compatibility with the refrigerant. In addition, the refrigerant should also demonstrate certain characteristics for better performance, such as a significant latent heat capacity, exact freezing point and saturation vapour pressure, non-flammability, good thermal stability, anti-toxicity, lack of corruption/adulteration, etc.
Unfortunately, there are few working pairs that completely fulfill the requirements discussed above. However, there are some working pairs that come close such as: $[34,35,38]$ :

1. silica gel/water,

2. activated-carbon/methanol,

3. activated-carbon/ammonia,

4. zeolite/water,

5. activated carbon granular and fiber adsorbent,

6. metal chloride/ammonia,

7. composite adsorbent/ammonia,

8. metal hydrides and hydrogen,

9. metal oxides and oxygen.

\subsubsection{Solar Physiorption Refrigeration Systems}

According to Wang DC et al. [35], in physisorption technology, the adsorbate molecules form a van der Waals interaction with surface molecules within a vacuum and clean 
environment instead of forming a chemical bond.

\subsubsection{Solar Chemisorption Refrigeration Systems}

Hassan HZ et al. [5] defined a chemisorption as a process in which the adsorbate and the adsorbent atoms form a complex compound by sharing their electrons in a chemical reaction process. A valence force is created that is stronger than the van der Waals interaction described in the physisorption process. To free the adsorbate, a very high heat of up to $800 \mathrm{~kJ} / \mathrm{mole}$ is required. It is a specific process that is suitable for a fixed gas and a fixed solid adsorbent. Moreover, it is a monovariant system, where physisorption is a divariant technique. One of the main advantage of chemisorption technology is a high COP [39]. A complete cycle of chemisorption technology consists of four consecutive processes: desorption, condensation, evaporation and adsorption [34].

\section{Exergy Analysis of Solar Refrigeration Technologies}

\subsection{The Necessity of Exergy Analysis of a System}

The working performance of refrigeration systems can be investigated based on the energy and exergy approaches. The former is obtained from the first law of thermodynamics, accounting the quantity of energy in the entire system. While the latter is based on the second law of thermodynamics which involves irreversibility and represents quality of energy in a system. The exergy based analysis is very important to indicate the cause, location and magnitude of the system inefficiencies and provides the true measure how a system approaches to the ideal [40, 41]. Many researchers propose also that the thermodynamic performance of a process is best evaluated using exergy analysis. Exergy analysis can be used to improve the efficiency of a system after determining the sources and the magnitude of irreversibility. Muhammad Faisal Hasan et al. [42] who did the exergy analysis of Serpentine Thermosyphon Solar Water Heater, predicted the performance of these type of systems by a summary of exergy destruction and loss, dimensionless exergy and exergy destruction ratio. Soteris A. Kalogirou et al. [43] presented a review on exergy analysis of solar thermal collectors and processes. R. Maryami and Dehghan [22] presented an exergetic analysis of all system's components after their energy analysis. The half effect, single effect, series class of double effect, parallel class of double effect and triple effect absorption refrigeration cycles were compared together in this study. The exergetic evaluation of the thermodynamic flows, which goes through this cycle, was performed for a refrigerating capacity $300 \mathrm{~kW}$. According to energetic and exergetic analysis, the results showed that the coefficient of performance and exergy efficiency increases from the half effect, to the single, double and triple effect refrigeration system while total exergy change approximately decreases. Golchoobian et al. [44] investigated exergy analysis of solar ejector refrigeration system (using R141) for air conditioning of building in Tehran (Iran). A significant improvement in exergetic performance of the system was observed using hot water storage tank. Higher exergy losses were also observed in collector followed by ejector. Overall, system irreversibility was found more during first and last working hours. G. Gutiérrez-Urueta et al. [45] conducted a study on the energy and exergy analysis of water- $\mathrm{LiBr}$ absorption systems with adiabatic absorbers for heating and cooling. Their results show that the coefficient of performance and the exergy efficiency were influenced by the temperature, these parameters increase with the increase of the absorber temperature. Sanju Thomas et al. [46] analyzed and identified the potential of using a standalone solar thermal energy generation unit for power, heating and cooling applications with some modifications in the LFR. Comparisons of adsorption and absorption methods are analyzed in the application of refrigeration. Energy, entropy and exergy analysis were done for the major components in solar thermal based polygeneration system. Vadiee A. and M. Yaghoubi [47] demonstrated that beside thermal energy analysis, an exergy analysis can lead to understand better the energy conservation potential. Many studies have been done on exergy analysis of solar cooling systems. The last review in this domain is that of M. U. Ahmadi P. et al. [48]. They conducted an exergy efficiency analysis on multigenerational energy system which generates power, water and cooling simultaneously. Siddiqui et al. [49], focused in their review on different solar powered absorption refrigeration systems, that is: diffusion absorption systems, ejector based absorption systems, compression absorption systems and cogeneration/trigeneration absorption systems. The thermodynamic properties of most common working fluids as well as use of ternary mixtures in solar powered absorption systems have been reviewed in this study. K. R. Ullah et al. [15] conducted a review on solar thermal refrigeration and cooling methods, the absorption and adsorption cycles were presented. Gebreslassie et al. [50] performed an exergy analysis for a lithium-bromide/water pair in a multiple-effect absorption system. They conducted a comparative exergy study among single-effect, double-effect and triple-effect absorption for unavoidable destruction. Sunil Kumar Sansaniwal et al. [40] presented a comprehensive review on energy and exergy analyses of various typical solar energy applications, they concluded that exergy efficiencies are highly dependent on the intensity of solar radiations on daily basis. Esa Dube Kerme et al. [51] analyzed the effects of generator inlet temperature, effectiveness of the solution heat exchanger and the pump mass flow rate on the energetic and exergetic performance of the chiller system. The examined performance parameters were coefficient of performance, exergetic efficiency, exergy destruction, fuel depletion ratio and improvement potential.

\subsection{Chronological and Statistical Works on Exergy Analysis}

Mr. Manish G. Vasava et al. [52] established a chronological and statistical work about the development 
scenario of exergy analysis in the world. In table 1, it is found that, exergy analysis has grown from child to adult from 1824 to till 2014 and scientists and researchers are enjoying the fruitful results of expertise in the field of Exergy analysis. In table 2 another chronological and statistical work have been done about the different fields of applications of exergy, it is clear that, since its development, exergy analysis has been widely used in most of the engineering applications. The study of exergy analysis related to VCRS has been increased in last decade only. It's can also be noted from those two tables that the fields of Cryogenics and Chemical Processes are very concerned by studies on exergy analysis before 2014 .

Table 1. Development Scenario of Exergy [52].

\begin{tabular}{lll}
\hline Sub Group & Duration of Year & Number of Research Papers Published \\
\hline Conceptual Literature in line of Exergy & $1824-1952$ & 33 \\
Inception of Exergy & 1953 & 1 \\
Development of Exergy analysis & $1954-1970$ & 71 \\
Expertise Phase of Exergy & After 1970 & 292 \\
\hline
\end{tabular}

Table 2. Application of Exergy Analysis [52].

\begin{tabular}{|c|c|c|c|c|c|}
\hline \multirow{2}{*}{$\begin{array}{l}\text { Type of Engineering Applications of exergy } \\
\text { analysis }\end{array}$} & \multicolumn{5}{|c|}{ Number of Research Papers Published } \\
\hline & 1931-1960 & 1961-1980 & 1981-2000 & 2001-2010 & 2011-2014 \\
\hline Steam Power Cycles & 2 & 4 & 5 & 5 & - \\
\hline Gas Turbine Cycles & - & 4 & 6 & 9 & - \\
\hline Renewable Energy Cycles & - & - & 4 & 1 & - \\
\hline Combined \& Cogeneration Cycles & - & 9 & 20 & 11 & - \\
\hline Heat exchangers \& Heat Networking & 1 & 5 & 18 & 8 & - \\
\hline Cryogenics & 4 & 15 & 14 & 12 & - \\
\hline Distillation \& Desalination & 1 & 6 & 15 & 8 & - \\
\hline Industrial \& Agricultural Systems & 2 & 6 & 22 & 8 & - \\
\hline Environmental Appli. & - & 8 & 21 & 12 & - \\
\hline VCRS & - & - & - & 5 & 8 \\
\hline
\end{tabular}

\subsection{Mathematical Equations for Exergy Analysis}

\subsubsection{Exergy}

The exergy is defined as the maximum possible reversible work that can be produced by a stream or system in bringing the state of the system with a reference environment. Exergy is conserved in an ideal process (except for those developing work) and destroyed during a real process. However, quality of energy is more important to identify work potential of system and is expressed by term 'exergy'. When exergy losses its quality in a process, it gets destroyed and thus affects the overall work performance. Therefore, energy is conserved while exergy is accumulated. As compared to low exergy content of energy, high exergy content is more important to obtain desirable performance of the system [53]. Therefore, the optimum design, resource utilization, sustainability and impact of the environment on energy may be investigated through exergetic analysis. Moreover, exergy analysis is helpful in assessing and comparing the various processes and systems meaningfully and rationally [18, 54]. Blanco-Marigorta et al. [55] identified the location, magnitude and the thermodynamic inefficiencies in a solar thermal power plant using exergy analysis. Exergy calculation is based on the second law of thermodynamics which deals with quantity and quality of energy relative to the reference state. Energy and exergy efficiencies are also known as first and second law efficiency, respectively. In general, exergy efficiency is often calculated to be lower than that of energy efficiency due to the involvement of irreversibilities caused by thermodynamics imperfections during the process $[41,56]$.

Many kinds of exergy are existing due to the presence of various random activities such as macroscopic forms of energy, turbulence flow of molecules and the concentration of species with respect to dead state [57]. Exergy performance of a system included exergetic efficiency, exergy losses, exergy improvement, coefficient of performance and exergetic coefficient of performance.

Neglecting nuclear, magnetic and electric effects, the exergy for a specific state with reference to the environment can be written as: [45]

$$
\dot{E}=\dot{m}\left(h-h_{0}\right)-T_{0}\left(s-s_{0}\right)
$$

where $\mathrm{h}_{0}$ and $\mathrm{s}_{0}$ are evaluated at the reference environment temperature $\mathrm{T}_{0}=293.15 \mathrm{~K}$ and atmospheric pressure. The subsequent analysis uses temperatures in $\mathrm{K}$.

Zhong Ge et al. [58] conducted a study on exergy analysis of a flat plate collector. The model was experimentally validated and the results show that the exergy performance could be significantly improved by adjusting the operating parameters which are solar irradiance, ambient temperature, fluid inlet temperature and fluid mass flow rate. One cannot undertake the exergy analysis of a solar system without taking into consideration the solar collector. Esa Dube Kerme et al. [51] examined the influence of the solar collector types on the collector efficiency and the useful heat gain by the collector for the best performance: 


$$
E_{u}=Q_{u}-m_{c o l} \cdot c_{p} \cdot T_{0} \cdot \ln \left(\frac{T_{c o l, o u t}}{T_{c o l, i n}}\right)
$$

Zhong Ge et al. [58] proposed a micro unit dA taken from the absorber plate in steady state according to the first law of thermodynamics:

$$
\partial Q_{u}=\partial Q_{s}-\partial Q_{l}=\left[S-U_{l}\left(T_{p}-T_{a}\right] d A\right.
$$

where $\mathrm{Q}_{\mathrm{u}}$ is the useful heat rate gain of the flat plate solar collector, $\mathrm{Q}_{\mathrm{s}}$ is the radiation flux absorbed by the absorption plate, $Q_{1}$ is the heat loss from the solar collector to the environment, $\mathrm{S}$ is the radiation flux absorbed by a unit area of the absorber plate, $\mathrm{U}_{1}$ is the local heat loss coefficient of $\mathrm{dA}, \mathrm{T}_{\mathrm{p}}$ is the temperature of $\mathrm{dA}$ and $\mathrm{T}_{\mathrm{a}}$ is the ambient temperature.

According to the integral mean value theorem, the following can be deduced from equation (3):

$$
\begin{gathered}
Q_{u}=\iint_{A p}\left[S-U_{l}\left(T_{p}-T_{a}\right)\right] d A=A_{p}\left[S \overline{\bar{U}}_{l}\left(\overline{\bar{T}}_{p}-T\right)\right] \\
N_{u}=1+1.44\left\{\left[\left|1-\frac{1708}{R a \cos \theta}\right|+\left(1-\frac{1708}{R a \cos \theta}\right)\right] / 2\right\}\left[1-\frac{(\sin 1.8 \theta)^{1.6} 1708}{R a \cos \theta}\right]+\left\{\left(\frac{R a \cos \theta}{5830}\right)^{\frac{1}{3}}-1 \mid+\left[\left(\frac{R a \cos \theta}{5830}\right)^{\frac{1}{3}}-1\right]\right\} / 2
\end{gathered}
$$

where

$$
R a=\frac{g \beta d^{3}\left(\bar{T}_{p}-T_{1}\right)}{\alpha V}
$$

and

$$
h_{c, p-1}=\frac{N_{u} K_{\text {air }}}{d}
$$

According to Evangelos Bellos et al. [59] the available solar irradiation in the collector level is calculated as follow:

$$
Q_{s}=A_{c} \cdot G_{T}
$$

The useful heat production of the collector field is calculated by the exergy balance on the fluid volume [58]:

$$
Q_{u}=m_{c} c_{p}\left(T_{c o l, o u t}-T_{c o l, \text { in }}\right)
$$

The thermal efficiency of the collector is the ratio of the useful heat to the available solar radiation on the collector level. It is given as follow [58]:

$$
\eta_{t h}=\frac{Q_{u}}{Q_{s}}
$$

The mass flow rate in the collector field is calculated according to the specific mass flow rate [58] as it is presented below: where $\mathrm{A}$ is the area of the absorber plate, $\overline{\bar{U}}_{l}$ is the integral average of $\mathrm{U}_{1}$ over the absorber plate, and $\overline{\bar{T}}_{p}$ is the integral average of $T_{p}$ over the absorber plate.

Taking a micro unit dy from the absorber plate, Zhong et al. [58] obtained the heat transferred from the absorber plate to the glass comprises radiative heat and convective heat. The radiative heat transfer from the absorber plate to the glass of dy is follows:

$$
\partial q_{r, p-1}=\frac{\sigma\left(\bar{T}_{p}^{4}-T_{1}^{4}\right)}{\frac{1-\varepsilon_{p}}{\varepsilon_{p} w}+\frac{1}{w}+\frac{1-\varepsilon_{1}}{\varepsilon_{1} w}}
$$

The convective heat transfer coefficient between the absorber plate and the glass is calculated from the Nusselt number according to the following equation [58]: by:

$$
\dot{m}_{c o l}=0.02 A_{c}
$$

The solar collector performance:

$$
\eta_{e x, s y s}=\frac{\dot{E}_{x}}{P_{e l}+E_{s o l}}
$$

The exergy collected from the collector's bottom is given

$$
\varepsilon_{Q}=Q\left(1-\frac{T_{0}}{T_{B}}\right)
$$

where $\mathrm{Q}$ is the heat extracted that is deliver to the user, $\mathrm{T}_{0}$ is the temperature of the dead state and $\varepsilon_{\mathrm{Q}}$ is the exergy extracted from the collector.

The coefficient of performance of a refrigeration system is given by [45]:

$$
C O P_{\text {cool }}=\frac{\dot{Q}_{e v}}{\dot{Q}_{g}+\dot{W}_{e l}}
$$

The exergetic coefficient of performance of the ejector absorption heat transformer is as follow [60]: 


$$
E C O P=\frac{q_{a}\left(1-\frac{T_{0}}{T_{a}}\right)}{q_{g}\left(1-\frac{T_{0}}{T_{g}}\right)+\dot{q}_{e}\left(1-\frac{T_{0}}{T_{e}}\right)+\dot{W}_{p 1 e}+\dot{W}_{p 2 e}}
$$

\subsubsection{Exergetic Efficiency}

G. Gutiérrez-Urueta et al. [45] investigated and concluded that the exergy efficiency of absorber and solution heat exchanger increases as the absorption temperature increases, but it shows a decreasing behaviour when generation temperatures increases. The results obtained allow also the identification of parameters that may influence the exergy efficiency of the adiabatic absorption system. In general, exergy efficiency is often calculated to be lower than that of energy efficiency due to the involvement of irreversibilities caused by thermodynamics imperfections during the process $[18,56]$. Baral et al. [61] investigated the energy and exergetic performance of a small scale solar assisted organic Rankine cycle (ORC) comprised of scroll expander, heat exchanger and reciprocating feed pump for electricity generation. The influence of various process parameters (evaporating and condensing pressure, the degree of superheating, pressure ratio, expander inlet and dead state temperature) on energy and exergy efficiencies of the system was studied. The overall thermal and exergy efficiencies of the system were obtained to be $7.5 \%$ and $43.7 \%$, respectively. Joshi et al. [62] investigated the working performance of hybrid $\mathrm{PV} / \mathrm{T}$ system in terms of energy and exergy efficiencies and improvement potential factors. The energy and exergy efficiencies of hybrid PV/ T system were found to be $45.0 \%$ and $16.0 \%$, respectively. Maryami and Dehghan [22] presented variations of exergetic efficiency based on the generator temperature for five configurations of absorption refrigeration systems at different condenser and evaporate temperatures. For all configurations (half to triple effect absorption refrigeration system) and each evaporator and condenser temperature, the exergetic efficiency increases up to a certain generator temperature and then decreases. In fact, the results show that for a given evaporator and condenser temperature, there was a minimum generator temperature which corresponds to maximum exergetic efficiency. It was considered that the exergetic efficiencies reach a maximum value at slightly lower generator temperatures than the COP. Furthermore, at the higher generator temperatures, while COP remains approximately constant for all absorption systems, exergetic efficiency decreases gradually for each value of evaporator and condenser operating temperature considered. The possible reason for this was that, when increasing the generator temperature negatively affects the exergetic efficiency value. Unlike the COP variation with evaporator and condenser temperatures in a certain generator temperature, it can be seen that the better exergetic efficiency of the system is achieved at lower condenser temperature and lower evaporator temperatures within the same generator temperature. Otherwise, exergetic efficiency decreases by increasing condenser and evaporator temperatures for a given generator temperature. Kaushik and Arora [63] achieved the 1st and 2nd law thermodynamic analysis of single effect and double effect $\mathrm{LiBr}$-water system which was connected in series. Their 1st law analysis results indicate that the COP of series flow double effect system was 60 to $70 \%$ greater than the single effect system where the optimum COP was reached at $91^{\circ} \mathrm{C}$ for single effect and $150^{\circ} \mathrm{C}$ for double effect system. Similarly their 2 nd law analysis results indicate that the optimum exergetic efficiency was reached at $80^{\circ} \mathrm{C}$ for single effect and $130^{\circ} \mathrm{C}$ for double effect system. Reddy et al [64] presented the exergetic performance of $50 \mathrm{MW}$ solar power plant having parabolic dish Stirling engine and detected that the energy and exergy efficiencies of whole system were obtained to be $77.8 \%$ and $32.0 \%$, respectively. Izquierdo et al. [65] concluded after their study that the double stage system has about $22 \%$ less exergetic efficiency than the single effect one and $32 \%$ less exergetic efficiency than the double effect one. In another study, Izquierdo et al. (2005) [66] observed that the exergetic efficiency of the double stage cycle considered was lower than that of the single and double effect cycles because it worked with heat at lower temperature. The double stage system had about $22 \%$ less exergetic efficiency than the single effect one and $32 \%$ less exergetic efficiency than the double effect one. Kuzgunkaya and Hepbasli [67] obtained that the exergy efficiencies of a ground source heat pump (GSHP) and whole system were reported to be $21.1 \%$ and $15.5 \%$, respectively. Yildiz and Ersoz [68] studied the simulation and experimentation for aquaammonia based diffusion absorption system with helium as the inert gas indicated that the energy efficiency was reported to be equal to 0.1858 whereas the exergy efficiency was reported as experimentally found to be 0.0356. Lostec et al. [69] implemented the second law optimization of an absorption refrigeration system. Their results indicated the presence of three optimum values of COP $0.56,0.62$ and 0.69 for the absorption system that minimizes UA value, irreversibility and exergetic efficiency respectively. R. Maryami et al. [22] give the variation range of maximum COP and exergetic efficiency and minimum total exergy change of some usual cycles in Table 3. Gunerhan and Hepbasli [70] presented the performance evaluation and exergetic modelling of solar water heating for residential applications. The exergy efficiencies of solar collector and whole system were reported to vary from $2.02 \%$ to $3.37 \%$ and $3.27-4.39 \%$, respectively.

The exergy efficiency is given as follows [40]:

$$
\varepsilon=\frac{\dot{E x_{o u t}}}{\dot{E} x_{i n}}=1-\frac{\dot{E x_{d}}}{E \dot{x}_{\text {in }}}
$$


Table 3. Variation range of maximum COP and exergetic efficiency and minimum total exergy change of the cycles. [22].

\begin{tabular}{llll}
\hline Cycle & COP [\%] & Exergetic efficiency [\%] & Total exergy change [kW] \\
\hline Half effect & $0.407-0.438$ & $9.781-18.28$ & $59.62-67.13$ \\
Single effect & $0.768-0.825$ & $13.43-24.03$ & $41.20-49.58$ \\
Series double effect & $1.217-1.397$ & $14.19-24.50$ & $41.00-55.46$ \\
Parallel double effect & $1.306-1.440$ & $15.33-23.63$ & $44.28-54.95$ \\
Triple effect & $1.482-1.905$ & $14.21-24.09$ & $65.06-232.1$ \\
\hline
\end{tabular}

Exergy efficiency is given by Sunil et al as [40]:

$$
\varepsilon=\eta_{0}(1-\beta \Delta T)+\eta_{t h}\left(1-\frac{T_{0}+273}{293+\Delta T}\right)
$$

The overall exergy efficiency of a system is given by [40]:

$$
\varepsilon=1-\left(\frac{\dot{E} x_{l o s s}+E x_{d}}{\dot{E} x_{\text {sun }}}\right)
$$

\subsubsection{Exergy Losses}

Another words to express exergy loss is exergy destruction or irreversibility. Reddy et al. [64] presented the exergetic performance of $50 \mathrm{MW}$ solar power plant having parabolic dish Stirling engine. The energetic and exergetic evaluation of each component (parabolic dish collector, Stirling engine, heat exchanger and cooling tower) were realised. The major energetic losses of $42.3 \mathrm{~kW}$ were observed in Stirling engine followed by collector receiver $(19.4 \mathrm{~kW})$. While the highest exergetic losses of $32.9 \mathrm{~kW}$ were reported in the collector receiver followed by Stirling engine $(22.1 \mathrm{~kW})[57]$. Esa Dube Kerme et al. [51] also indicated that the main source of the exergy destruction is the solar collector. In the solar collector, $71.9 \%$ of the input exergy was destroyed which accounted for $84 \%$ of the total exergy loss. Additionally, $7.1 \%$ of the inlet exergy was lost in the generator which was equivalent to $8.3 \%$ of the total exergy loss. The overall exergetic improvement potential of the system was approximately $84.7 \%$. Kilic and Kaynakli. [71] performed the 1st and 2nd law thermodynamic analysis of $\mathrm{LiBr}$-water absorption chiller. Their results indicated that irrespective of the working conditions, the generator presents the highest exergy loss component i.e. $45.6 \%$ of the overall exergy loss in the chiller while the pump and refrigerant heat exchanger represents the lowest exergy loss component in the chiller. Therefore, exergy loss (exergy waste and exergy destruction) indicates possible improvement in overall performance of the system. [40] Lostec et al. [69] results showed that $33 \%$ and $34 \%$ of the exergy destruction takes place inside the absorber and desorber of the absorption system respectively. Onan et al. [72] utilized MATLab software to simulate the hourly performance of a $106 \mathrm{~kW}$ system in an environment where the ambient temperature varies from $40.3^{\circ} \mathrm{C}$ to $13.2^{\circ} \mathrm{C}$. Their results indicated that the total exergy loss in the collector ranges from 10 to $70 \%$ which is the maximum compared to the other components of the solar powered LiBr-water system. Yildiz and Ersoz. [68] performed both the simulation and experimentation for aquaammonia based diffusion absorption system with helium as the inert gas. It was reported that the highest energy and exergy losses occurs in the solution heat exchanger which was experimentally determined to be $44.4 \%$ and $64 \%$ respectively of the total energy and exergy losses in the system. They also reported that the lowest exergy loss occurs in the condenser. Ahamed et al. [73] demonstrated that exergy losses in the components decrease with the increase of evaporating temperature. The higher the temperature differences in any component with the surroundings, the higher the exergy loss. Arora and Kaushik. [74] explained that much research is done to find the exergy destruction in the different components of the vapour components with different refrigerants. The efficiency defects in the compressor, condenser, throttle vale and evaporator. While investigating the working performance of a hybrid PV/T system in terms of energy and exergy efficiencies and improvement potential factors, Joshi et al. [62] obtained exergetic improvement potential of 250-610 $\mathrm{W}$, corresponding to the exergy destructions.

The exergy destruction [45]:

$$
\dot{I}=\sum_{j}\left(1-\frac{T_{0}}{T_{j}}\right) Q_{j}+\left(\sum_{k=1}^{n} \dot{m}_{k} \dot{\dot{E}_{k}}\right)-\left(\sum_{k=1}^{n} m_{k} \dot{E}_{k}\right)-W
$$

\subsubsection{Exergy Improvement}

The exergy improvement is an important criterion in optimum designing of solar systems and can be achieved through minimizing exergy losses or irreversibilities occurred in the process [40]. Kuzgunkaya and Hepbasli [67] experimentally studied the exergetic performance of a ground source heat pump (GSHP) dryer for drying laurel leaves. The maximum potential of exergetic improvement was calculated to be $551.63 \mathrm{~W}$ by using expression given by [75]. Recently, Fudholi et al. [75] also investigated energy and exergy analyses of a hybrid solar drying system for drying silver jewfish. The collector and dryer efficiency were obtained to be $41.0 \%$ and $23.0 \%$, respectively (for mass flow rate of $0.0778 \mathrm{~kg} / \mathrm{s}$ and solar radiation of $540 \mathrm{~W} / \mathrm{m}^{2}$ ). The average exergetic improvement potential of $236 \mathrm{~W}$ was also calculated [40].

The exergy improvement potential is as follow [40]:

$$
I P=(1-\varepsilon) \dot{E x_{d}}
$$

\subsubsection{Exergetic Coefficient of Performance}

The overall exergy input to the solar powered absorption cooling system is the exergy of the solar radiation falling on 
the solar collector, and it is the function of the sun's outer surface temperature $\left(\mathrm{T}_{\mathrm{s}}=6000 \mathrm{~K}\right)$ and defined as [76]:

$$
\dot{E}_{x, \text { in }}=A_{c} I_{T}\left(1+\frac{1}{3}\left(\frac{T_{0}}{T_{s}}\right)^{4}-\frac{4}{3}\left(\frac{T_{0}}{T_{s}}\right)\right)
$$

The irreversibility ratio of each component of solar driven absorption cooling system is defined as the ratio of exergy destroyed in each component to that of the total exergy loss of the system and it is given by [77]:

$$
I R=\frac{\dot{E}_{x d}}{\dot{E}_{x d, \text { total }}}
$$

Aman et al. [78] observed more irreversibility in absorber $(63 \%)$ followed by generator $(13 \%)$ and condenser $(11 \%)$. The value of COP of the system was obtained to be 1.86 , however, this value was reported to decrease (up to 0.60) due to exergy degradation of all components of the system. The overall efficiency of cooling system was found lower as compared to $\mathrm{LiBr}-\mathrm{H}_{2} \mathrm{O}$ based cooling and thus latter was recommended to achieve the higher exergetic performance. The exergy efficiency of different solar power systems (solar power tower, solar thermal power plant, solar gas power turbine, dish/engine, Kalina, Rankine and Brayton cycle) are observed to vary from $6.0-43.7 \%$. The highest exergy destructions are caused by heliostat field, receiver and evaporator. Also, the waste heat from different power cycles can be utilized in combination with high grade energy for performance enhancements.

R. Gomri et al. [79] presented in Figures 12 and 13 the relation between exergy efficiency, COP and the temperature of HPG and LPG in a double effect absorption refrigeration system. These figures can be taken as a model for the variation of the coefficient of performance and the exergy efficiency of a system with the temperature of the generators in a double effect refrigerator.

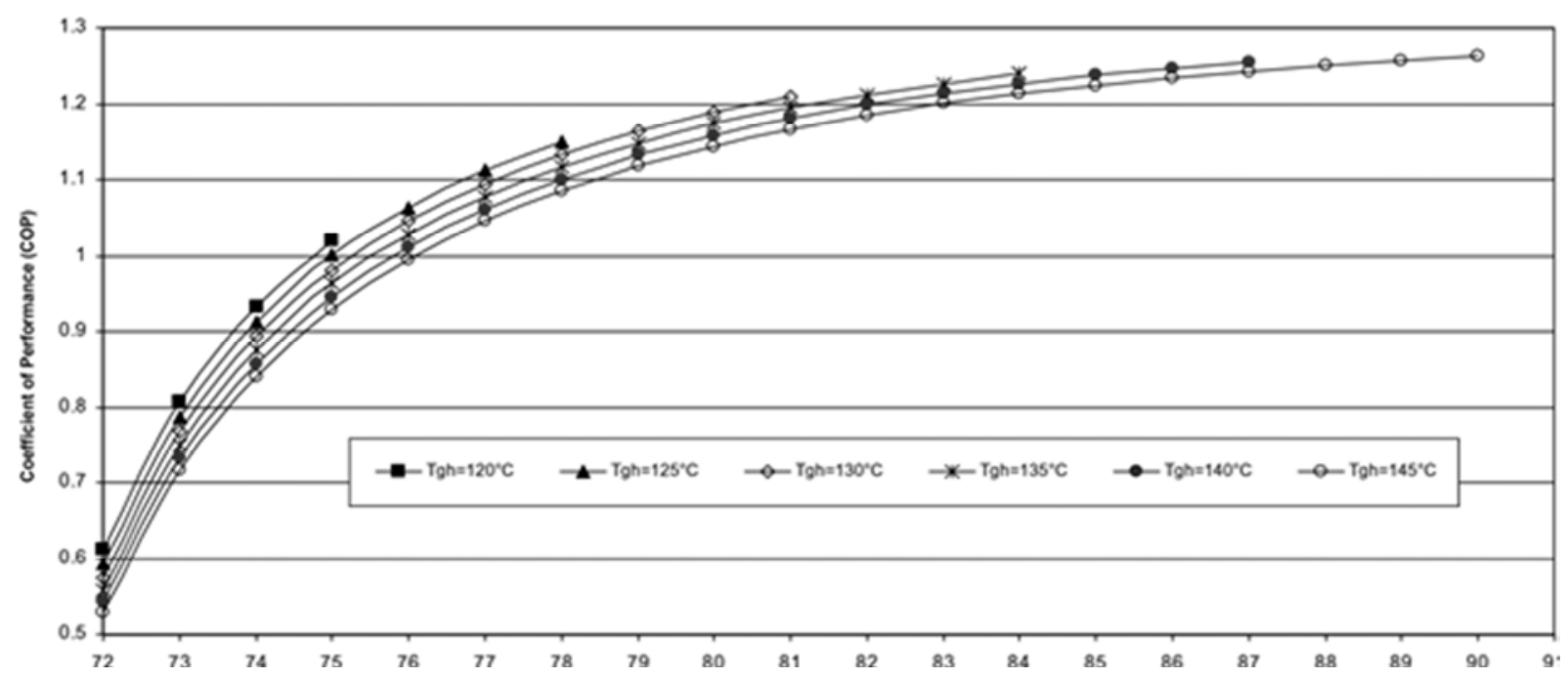

Figure 12. Coefficient of performance (COP) of double effect absorption refrigeration system versus HPG and LPG temperatures. [79].

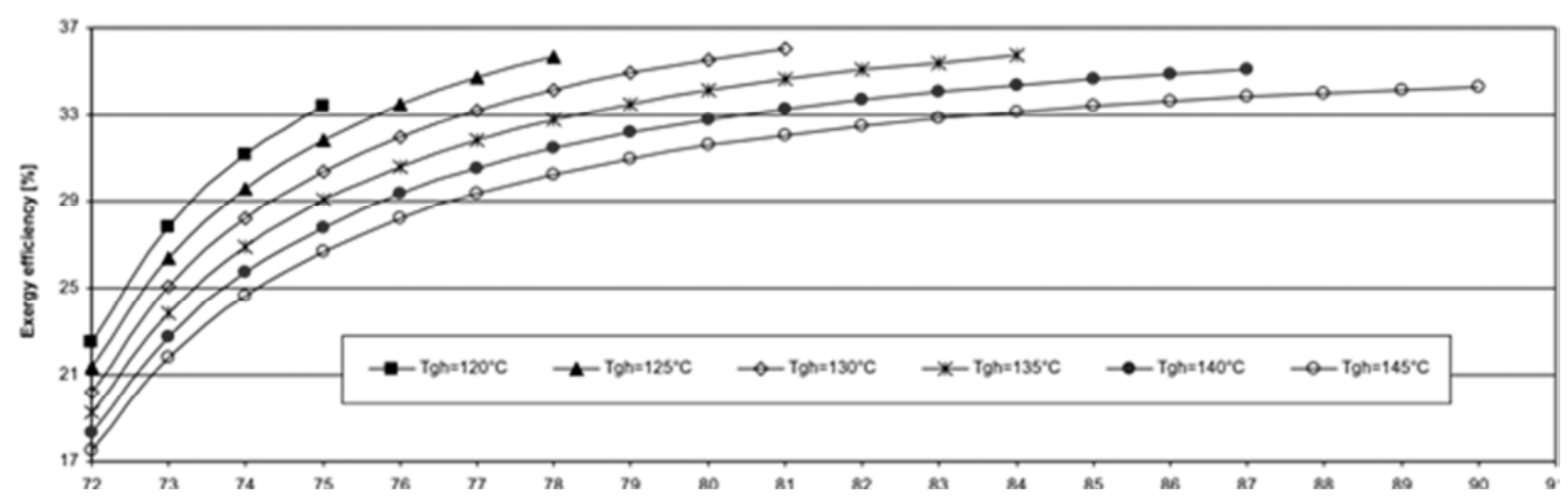

Figure 13. Exergy efficiency of double effect absorption refrigeration system versus HPG and LPG temperatures [79].

They also presented a T-s diagram of a $\mathrm{LiBr} /$ water double effect absorption refrigeration cycle in Figure 14. This diagram is particularly interesting in interpreting and also for a better comprehension of the exergy analysis of a refrigeration cycle. 


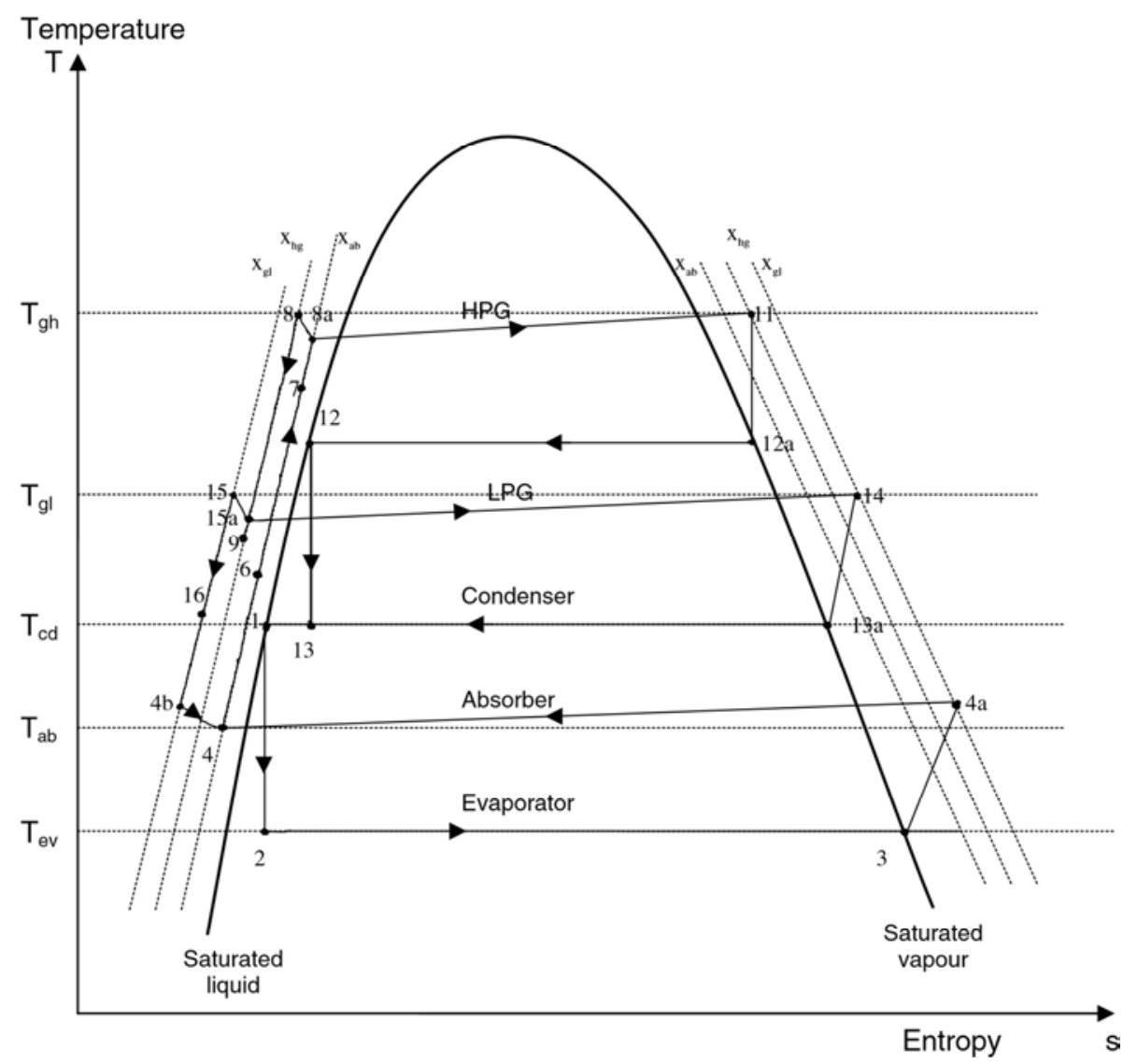

Figure 14. LiBr/water double effect absorption refrigeration cycle on T-s diagram. [79].

The maximum improvement in the exergy efficiency for a system is achieved when the exergy loss (irreversibility) is minimized. As a result, it is useful to employ the concept of an exergetic improvement potential when analyzing different processes of a system. Improvement potential for a component is an avoidable portion of the exergy destruction rate through technological (design) improvement of the component. This improvement potential in the rate form, denoted by IP_, is given by [80]:

$$
I \dot{P}=\left(1-\eta_{\text {exergy }}\right) \dot{E}_{x d}
$$

The work potential of a real system can only be estimated by defining a state corresponding to zero work potential because the equilibrium condition is technically correct for reference state. In exergy analysis, both mass and energy conservation principles may be applied together for design and analysis of different solar energy systems. The ideality, location, type and magnitude of various losses occurred in process can be identified and rectified accordingly.

\section{Conclusion}

This literature review discussed the exergy analysis of solar powered technologies, it's also a presentation of different refrigeration systems powered by solar energy, that is solar absorption and adsorption systems. The exergetic coefficient of performance, the coefficient of performance, the exergy loss and the exergy efficiency are the main parameters of a refrigeration system that has been exergically analysed. In this regard, exergy analysis is a very useful tool which can be successfully used in the performance evaluation of a solar refrigeration system. The solar collector which is an important component of a solar refrigeration has also retained our attention in this review. It is hoped that this contribution will simulate wider interest in the exergy analysis of solar refrigeration systems. We expected it should be useful for any newcomer in this field of technology.

\section{Nomenclature}

COP: coefficient of performance

ECOP: exergy coefficient of performance

E: exergy $(\mathrm{kJ} / \mathrm{kg})$

$\mathrm{f}$ : circulation ratio

h: enthalpy $(\mathrm{kJ} / \mathrm{kg})$

$\mathrm{s}$ : entropy $(\mathrm{kJ} / \mathrm{kgK})$

$\mathrm{m}$ : mass flow rate $(\mathrm{Kg} / \mathrm{s})$

$\mathrm{Q}$ : heat flow rate $(\mathrm{KW})$

$\mathrm{T}$ : temperature $\left({ }^{\circ} \mathrm{C}\right.$ or $\left.\mathrm{K}\right)$

$\mathrm{U}$ : heat loss coefficient $\left(\mathrm{W} / \mathrm{m}^{2} . \mathrm{K}\right)$

$\mathrm{T}$ : temperature $\left({ }^{\circ} \mathrm{C}, \mathrm{K}\right)$

Q: heat $(\mathrm{kJ})$

g: gravity $\left(\mathrm{m}^{2} / \mathrm{s}\right)$

I: irreversibility $(\mathrm{kJ} / \mathrm{kg})$

$\mathrm{W}$ : pump power $(\mathrm{kW})$ 
$\mathrm{Nu}$ : Nusselt number

Ra: Rayleigh number

$\mathrm{S}$ : radiative flux absorbed by a unit of the absorber plate $\left(\mathrm{W} / \mathrm{m}^{2}\right)$

Ac: aperture area $\left(\mathrm{m}^{2}\right)$

Ap: area of the absorber plate $\left(\mathrm{m}^{2}\right)$

$\mathrm{Cp}$ : heat capacity of the fluid (J/kg.K)

Ed: exergy loss rate $(\mathrm{w})$

$\mathrm{I}$ : solar irradiance $\left(\mathrm{W} / \mathrm{m}^{2}\right)$

Subscripts

B: bottom

$\mathrm{g}$ : generator

e: evaporator

a: absorber

c: condenser

p: planet

h: heat

W: work

u: useful

th: thermal

ex: exergetic

el: electric

sol: solar

1: local

sun: sun

col: collector

in: inlet

total: total

out: outlet

1: loss

s: solar

Greek letters

$\varepsilon$ : exergy

$\alpha$ : thermal diffusivity $\left(\mathrm{m}^{2} / \mathrm{s}\right)$

$\delta$ : fin thickness $(\mathrm{m})$

$\theta$ : collector tilt relative to the horizontal $\left(^{\circ}\right)$

$\eta$ : efficiency

$\sigma$ : Stefan-Boltzmann constant $\left(\mathrm{w} / \mathrm{m}^{2} \mathrm{k}^{4}\right)$

$\lambda$ : thermal conductivity of the fins $(\mathrm{w} / \mathrm{m} . \mathrm{K})$

$\beta$ : thermal expansion coefficient $\left(\mathrm{K}^{-1}\right)$

\section{References}

[1] Jafari, A., Haghighi Poshtiri, A., Passive solar cooling of single-storey buildings by an adsorption chiller system combined with a solar chimney. J. Clean. Prod. 2017; 141, 662-682.

[2] Said, Z., Saidur, R., Rahim, N. A., Energy and exergy analysis of a flat plate solar collector using different sizes of aluminium oxide based nanofluid. J. Clean. Prod. 2016; 133, 518-530.

[3] Chafidz, A., Al-Zahrani, S., Al-Otaibi, M. N., Hoong, C. F., Lai, T. F., Prabu, M., Portable and integrated solar-driven desalination system using membrane distillation for arid remote areas in Saudi Arabia. Desalination 2014; 345, 3649.
[4] Kalogirou, S. A. Solar Energy Engineering: Processes and Systems. Academic Press. 2013.

[5] Hassan H, Mohamad A. A review on solar cold production through absorption technology. Renewable and Sustainable Energy Reviews 2012; 16: 5331-5348.

[6] S. W. Sharshir, A. H. Elsheikh, Guilong Peng, Nuo Yang, M. O. A El-Samadony, A. E. Kabeel. Thermal performance and exergy analysis of solar stills: A review. Renewable and Sustainable Energy Reviews 73 (2017) 521-544.

[7] Szargut J. Second law analysis of energy devices and processes International progress in second law analysis. Energy 1980; 5: 709-18.

[8] Ziegler F, Alefeld G. Coefficient of performance of multistage absorption cycles. International Journal of Refrigeration 1987; 10 (5): 285-95.

[9] Gungor Afsin, Bayrak Mustafa, Beylergil Bertan. In view of sustainable future energetic-exergetic and economic analysis of a natural gas cogeneration plant. Int J Exergy 2013; 12 (No. 1): $109 \mathrm{e} 18.436$.

[10] Maurice Tenkeng, Paiguy Armand Ngouateu Wouagfack, Réné Tchinda. Exergy Analysis of a Double-Effect Solar Absorption Refrigeration System in Ngaoundere World Journal of Engineering and Technology 2019; 7: 158-174.

[11] Maurice Tenkeng, Paiguy Armand Ngouateu Wouagfack, Réné Tchinda. Exergy Analysis of a Solar Absorption Refrigeration System in Ngaoundere. Journal of Power and Energy Engineering 2017; 5: 1-18.

[12] Saidur R, Masjuki H, Hasanuzzaman M, Mahlia T, Tan C, Ooi $\mathrm{J}$, et al. Performance investigation of a solar powered thermoelectric refrigerator. International Journal of Mechanical and Materials Engineering 2008; 3: 7-16.

[13] Kalkan N, Young EA, Celiktas A. Solar thermal air conditioning technology reducing the footprint of solar thermal air conditioning. Renewable and Sustainable Energy Reviews 2012; 16: 6352-6383.

[14] Hassan HZ, Mohamad AA, Al-Ansary HA. Development of a continuously operating solar-driven adsorption cooling system: thermodynamic analysis and parametric study. Applied Thermal Engineering 2012; 48: 332-341.

[15] K. R. Ullah, R. Saidur, H. W. Ping, R. K. Akikur, N. H. Shuvo A review of solar thermal refrigeration and cooling methods. Renewable and Sustainable Energy Reviews 24 (2013) 499 513.

[16] Chidambaram LA, Ramana AS, Kamaraj G, Velraj R. Review of solar cooling methods and thermal storage options. Renewable and Sustainable Energy Reviews 2011; 15: 3220-8.

[17] Zohar A, Jelinek M, Levy A, Borde I. Performance of diffusion absorption refrigeration cycle with organic working fluids. International Journal of Refrigeration 2009; 32 (6): 1241-6.

[18] Dincer I, Rosen MA. Exergy: energy environment and sustainable development. Elsevier; 2007, ISBN: 0080445292, EAN: 9780080445298.

[19] Sencan A, Yakut KA, Kalogirou SA. Exergy analysis of lithium bromide/water absorption systems. Renewable energy, 2005; 30: 645-657. 
[20] Kaushik SC, Yadav YK. Thermodynamic design and assessment of hybrid double absorption solar cooling systems. Heat Recovery Systems and CHP 1991; 11 (4): 255.

[21] Kaushik SC, Kaudinya JV. Open cycle absorption cooling-a review. Energy Conversion and Management 1989; 29 (2): 89-109.

[22] R. Maryami, A. A. Dehghan. An exergy based comparative study between $\mathrm{LiBr} /$ water absorption refrigeration systems from half effect to triple effect. Applied Thermal Engineering 2017 124; 103-123.

[23] Romero RJ, Guillen L, Pilatowsky I. Monomethylaminewater vapour absorption refrigeration system. Applied Thermal Engineering 2005; 25 (5-6): 867-876.

[24] Boopathi Raja V, Shanmugam V. A review and new approach to minimize the cost of solar assisted absorption cooling system. Renewable and Sustainable Energy Reviews 2012; 16: $6725-6731$.

[25] Hassan HZ, Mohamad AA. A review on solar-powered closed physisorption cooling systems. Renewable and Sustainable Energy Reviews 2012; 16: 2516-2538.

[26] Chen J, Kim KJ, Herold KE. Performance enhancement of a diffusion-absorption refrigerator. International Journal of Refrigeration 1996; 19 (3): 208-218.

[27] Hellmann HM, Grossman G. Simulation and analysis of an open-cycle dehumidifier-evaporator-regenerator (DER) absorption chiller for low grade heat utilization. International Journal of Refrigeration 1995; 18 (3): 177-189.

[28] Trombe F, Foex M. The production of cold by means of solar radiation. Sol Energy 1957; 1 (1): 51-52.

[29] Venkatesh A, Mani A. Comparison of performances of single stage and two stage intermittent ammonia-water solar refrigeration systems. Solar \& Wind Technology 1989; 6 (1): $75-78$.

[30] Staicovici MD. An autonomous solar ammonia-water refrigeration system. Solar Energy 1986; 36 (2): 115-124.

[31] Pridasawas W. Solar driven refrigeration systems with focus on the ejector cycle. PhD thesis, Royal Institute of Technology Stockholm, Sweden; 2006.

[32] Yeo THC, Tan IAW, Abdullah MO. Development of adsorption airconditioning technology using modified activated carbon - a review. Renewable and Sustainable Energy Reviews 2012; 16: 3355-3363.

[33] Choudhury B, Saha BB, Chatterjee PK, Sarkar JP. An overview of developments in adsorption refrigeration systems towards a sustainable way of cooling. Applied Energy 2013; 104: $554-567$.

[34] Wang LW, Wang RZ, Oliveira RG. A review on adsorption working pairs for refrigeration. Renewable and Sustainable Energy Reviews 2009; 13: 518-534.

[35] Wang DC, Li YH, Li D, Xia YZ, Zhang JP. A review on adsorption refrigeration technology and adsorption deterioration in physical adsorption systems. Renewable and Sustainable Energy Reviews 2010; 14: 344-353.

[36] Hildbrand C, Dind P, Pons M, Buchter F. A new solar powered adsorption refrigerator with high performance. Solar Energy 2004; 77: 311-8.
[37] El Fadar A, Mimet A, Perez-Garcia M. Modeling and study of a continuous adsorption-refrigeration system driven by a parabolic trough collector. International Journal of Solar Energy 2009; 83: 850-861.

[38] Askalany AA, Salem M, Ismael IM, Ali AHH, Morsy MG, Saha BB. An overview on adsorption pairs for cooling. Renewable and Sustainable Energy Reviews 2013; 19: 565-572.

[39] Wang L, Ziegler F, Roskilly AP, Wang R, Wang Y. A resorption cycle for the cogeneration of electricity and refrigeration. Applied Energy 2013; 106: 56-64.

[40] Sunil Kumar Sansaniwal, Vashimant Sharma, Jyotirmay Mathur. Energy and exergy analyses of various typical energy applications: A comprehensive review. Renewable and Sustainable Energy Reviews 82 (2018) 1576-1601.

[41] Dincer I, Hussain MM, Al-Zaharnah I. Energy and exergy use in public and private sector of Saudi Arabia. Energy Policy 2004; 32 (141): 1615-24.

[42] Muhammad Faisal Hasan, Md. Sayeed Ur Rahim Mahadi, Takahiko Miyazaki, Shigeru Koyama, Kyaw Thu. Exergy Analysis of Serpentine Thermosyphon Solar Water Heater. Appl. Sci. 2018, 8, 391.

[43] Soteris A. Kalogirou, Sotirios Karellas, Viorel Badescu, Konstantinos Braimakis. Exergy analysis on solar thermal systems: A better understanding of their sustainability. Renewable Energy 85 (2016) 1328-1333.

[44] Golchoobian H, Behbahaninia A, Amidpour M, Pourali O. Dynamic Exergy Analysis of a Solar Ejector Refrigeration System with Hot Water Storage Tank. Progress in Sustainable Energy Technologies: Generating Renewable Energy (Ed. Dincer), Chapter 17; p. 327-337; 2014. http: //dx.doi.org/DOI: 10.1007/978-3319-07896-0_17.

[45] G. Gutiérrez-Urueta* ${ }^{\mathrm{a} *}$ A. Huicochea ${ }^{\mathrm{b}}$, P. RodríguezAumente $^{c}$, W. Rivera. Energy and exergy analysis of water$\mathrm{LiBr}$ absorption systems with adiabatic absorbers for heating and cooling. Energy Procedia 57 (2014) 2676-2685.

[46] Sanju Thomas, Ajith Kumar G., Sudhansu S. Sahoo, Shinu Varghese. Energy and Exergy Analysis of Solar Thermal Energy-based Polygeneration Processes for Applications in Rural India. International Energy Journal2018; 18: 243-256.

[47] Vadiee A. and M. Yaghoubi. Exergy analysis of the solar blind system integrated with a commercial solar greenhouse. International Journal of Renewable Energy Research 2016; 6 (3): 1189-1199.

[48] Ahmadi P., Dincer I., Rosen M. A. Thermodynamic modelling and multi-objective evolutionary based optimisation of anew multigenerational energy system. Energy Conservation Management 2013; 76: 282-300.

[49] M. U. Siddiqui and S. A. M. Said. A review of solar powered absorption systems. Renewable and Sustainable Energy Reviews 42 (2015) 93-115.

[50] Gebreslassie BH, Medrano M, Boer D. Exergy analysis of multi-effect water- $\mathrm{LiBr}$ absorption systems: from half to triple effect. Renewable Energy 2010; 35: 1773-1782.

[51] Esa Dube Kerme, Achmad Chafidz, O. Philips Agboola, Jamel Orfi, Anis H. Fakeeha, Ahmed S. Al-Fatesh. energetic and exergetic analysis of solar-powered of lithium-bromide water absorption cooling system. Journal of Cleaner Production 2017; 151: 60-73. 
[52] Mr. Manish G. Vasava, Dr. Neeraj K. Chavda. Exergy Analysis of a Chilling Plant-A Review. Int. Journal of Engineering Research and Applications. www.ijera.com ISSN: 2248-9622, Vol. 4, Issue 5 (Version 6), May 2014, 124-128.

[53] I. Dincer, M. A. Rosen, Exergy: Energy Environment and Sustainable Development, Elsevier, 2007.

[54] Dincer I, Cengel YA. Energy, entropy and exergy concepts and their roles in thermal engineering. Entropy 2001; 3: 116-49.

[55] A. M. Blanco-Marigorta, M. Victoria Sanchez-Henríquez, J. A Peña-Quintana, Exergetic comparison of two different cooling technologies for the power cycle of a thermal power plant, Energy 36 (4) (2011) 1966-1972.

[56] Kilkis IB. Utilization of wind energy in space heating and cooling with hybrid. Energy Build 1999; 30: 147-153.

[57] Hermann WA. Quantifying global exergy resources. Energy 2006; 31 (12): 1685-1702.

[58] Zhong Ge, Huitao Wang, Hua Wang, Songyuan Zhang, Xin Guan. Exergy Analysis of Flat Plate Solar Collectors. Entropy 2014, 16, 2549-2567.

[59] Evangelos Bellos, Ioannis-Christos Theodosiou, Loukas Vellios, Christos Tzivanidis. Investigation of a novel solardriven refrigeration system with ejector. Thermal Science and Engineering Progress 8 (2018) 284-295.

[60] Sozen A, Menlik T, Ozbas E. The effect of ejector on the performance of diffusion absorption refrigeration systems: an experimental study. Applied Thermal Engineering 2012; 3344: 44-53.

[61] Baral S, Kim D, Yun E, Kim KC. Energy, exergy and performance analysis of small scale organic Rankine cycle systems for electrical power generation applicable in rural areas of developing countries. Energies 2015; 8 (2): 684-713.

[62] Joshi AS, Dincer I, Reddy BV. Analysis of energy and exergy efficiencies for hybrid $\mathrm{PV} / \mathrm{T}$ systems. Int $\mathrm{J}$ Low Carbon Technol 2011; 6 (1): 64-9.

[63] Kaushik SC, Arora A. Theoretical analysis of $\mathrm{LiBr} / \mathrm{H}_{2} \mathrm{O}$ absorption refrigeration systems. International Journal of Energy Research 2009; 33 (15): 1321-40.

[64] Reddy VS, Kaushik SC, Tyagi SK. Exergetic analysis and performance evaluation of parabolic dish Stirling engine solar power plant. Int J Energy Res 2013; 37 (11): 1287-1301.

[65] Izquierdo $M$, Venegas $M$, García N, Palacios E. Exergetic analysis of a double stage $\mathrm{LiBr}-\mathrm{H}_{2} \mathrm{O}$ thermal compressor cooled by air/water and driven by low grade heat. Energy Convers Manage 2005; 46 (7-8): 1029-1042.

[66] Izquierdo $M$, Venegas $M$, Rodrıguez $\mathrm{P}$, Lecuona $\mathrm{A}$.
Crystallization as a limit to develop solar air-cooled $\mathrm{LiBr}-$ $\mathrm{H}_{2} \mathrm{O}$ absorption systems using low-grade heat. Solar Energy Materials and Solar Cells 2004; 81 (2): 205-216.

[67] Kuzgunkaya EH, Hepbasli A. Exergetic performance assessment of a ground source heat pump drying system. Proceedings World Geothermal Congress 2010; 1-10.

[68] Y1ldız A, Ersöz MA. Energy and exergy analyses of the diffusion absorption refrigeration system. Energy 2013; 60: 407-15.

[69] Lostec BL, Galanis N, Millette J. Experimental study of an ammonia-water absorption chiller. Int J Refrig 2012; 35: $2275-2286$.

[70] Gunerhan H, Hepbasli. Exergetic modelling and performance evaluation of solar water heating systems for building applications. Energy Build 2007; 39 (5): 509-16.

[71] Kilic M, Kaynakli O. Second law-based thermodynamic analysis of water-lithium bromide absorption refrigeration system. Energy 2007; 32: 1505-1512.

[72] Onan C, Ozkan DB, Erdem S. Exergy analysis of a solar assisted absorption cooling system on an hourly basis in villa applications. Energy 2010; 35: 5277-5285.

[73] J. U. Ahamed, R. Saidur, H. H. Masjuki. A review on exergy analysis of vapor compression refrigeration system. Renewable and Sustainable Energy Reviews 2011; 15: 1593 1600 .

[74] Arora A, Kaushik SC. Theoretical analysis of $\mathrm{LiBr} / \mathrm{H}_{2} \mathrm{O}$ absorption refrigeration systems. International Journal of Energy Research 2009; 33: 1321-1340.

[75] Fudholi A, Yendra R, Basri DF, Ruslan MH, Sopian K. Energy and exergy analysis of hybrid solar drying system. Contemp Eng Sci 2016; 9 (5): 215-23.

[76] Petela, R.,. Exergy analysis of the solar cylindrical-parabolic cooker. Sol. Energy 2005; 79: 221-233.

[77] Bejan, A., Tsatsaronis, G. Thermal design and Optimization. John Wiley \& Sons. 1996.

[78] Aman J, Ting DSK, Henshaw P. Residential solar air conditioning: energy and exergy analyses of an ammoniawater absorption cooling system. Appl Therm Eng 2014; 62 (2): 424-32.

[79] Rabah Gomri, Riad Hakimi. Second law analysis of double effect vapour absorption cooler system. Energy Conversion and Management 2008; 49: 3343-3348.

[80] Hepbasli, A., A key review on exergetic analysis and assessment of renewable energy resources for a sustainable future. Renew. Sust. Energy. Rev 2008; 12: 593-661. 